\title{
Régimen estatutario del personal de administración y servicios funcionario de las universidades públicas
}

\author{
Agustín Juan Gil Franco
}

Funcionario de la Escala Técnica de Universidades, al servicio del Ayuntamiento de Madrid. Doctor en Derecho. Profesor de Derecho Administrativo Universidad Politécnica de Madrid

I. SITUACIÓN CON ANTERIORIDAD A LA LEY ORGÁNICA 6/2001. LA LEY DE REFORMA UNIVERSITARIA DE 25 DE AGOSTO DE 1983. II. EL PROGESO DE TRANSFERENCIAS A LAS COMUNIDADES AUTÓNOMAS EN MATERIA DE UNIVERSIDADES 1. Universidades transferidas a las CG.AA "históricas". 2. Universidades transferidas a las Comunidades Autónomas que accedieron a la autonomía por la vía del artículo 143 de la Constitución. III. LEGISLACIÓN ESTATAL DE DESARROLLO DE APLICACIÓN DIRECTA AL PAS FUNCIONARIO DE LAS UNIVERSIDADES PÚBLICAS. IV. LA LEY ORGÁNICA 6/2001, DE 21 DE DICIEMBRE, DE UNIVERSIDADES Y EL RÉGIMEN ESTATUARIO DEL PAS FUNCIONARIO DE LAS UNIVERSIDADES PÚBLICAS. 1. "El personal funcionario de administración y servicios se regirá por la presente Ley y sus disposiciones de desarrollo..." a) Composición del PAS funcionario b) Movilidad y carrera administrativa del PAS funcionario. c) Participación institucional del PAS funcionario. 2. "...Se regirá además por la legislación general de funcionarios, que le sea de aplicación y, en su caso por las disposiciones de desarrollo de ésta que elaboren las Comunidades Autónomas...” 3. “...y por los Estatutos de su Universidad." ¿Podrían constituir éstos formalmente el Estatuto jurídico peculiar del PAS funcionario? V. CONCLUSIONES VI. BIBLIOGRAFIA

RESUMEN:

En el trabajo se analiza la escasa legislación dedicada al personal funcionario de administración y servicios de las universidades públicas desde su ley "cabecera", la Ley orgánica de Universidades, y con ello la dificultad de desentrañar su régimen estatuto específico, y su posible incardinación en la función pública de las adminis- 
traciones territoriales competentes en esta materia. Se ha señalado además la extraordinaria importancia que la mencionada Ley orgánica otorga a los Estatutos de las universidades, la inexistencia de Decretos transferencia de este personal a las CG.AA y el mayor peso normativo que tiene la legislación estatal respecto a su régimen estatutario. Todo lo cual nos hace concluir que son funcionarios estatales.

\section{PALABRAS CLAVES:}

Universidades, funcionarios, personal de administración y servicios, estatuto de los funcionarios, sistema de fuentes.

\section{ABSTRACT:}

There is a poor legislation dedicated to civil servant administration and services of public universities from the main law, the Organic Law of Universities, and thus difficult to disentangle the specific status regime, and its potential incardination is analyzed dealing with the public role of the competent local authorities in this matter. Noticed the extraordinary importance that the aforementioned organic law grants to the Statutes of the universities, the lack of transfer of such personnel to the Autonomous Communities and the major regulatory relevance of the state legislation regarding its statutory regime. Everything leads to the conclusion that they are state officials.

\section{KEY WORDS:}

Universities, officers, administrative staff and services, status of staff, font system

\section{SITUACIÓN CON ANTERIORIDAD A LA LEY ORGÁNICA 6/2001. LA LEY DE REFORMA UNIVERSITARIA DE 25 DE AGOSTO DE 1983}

Nunca ha sido fácil determinar el régimen jurídico real del PAS funcionario de las universidades públicas. Previamente a la promulgación de la Ley Orgánica 11/1983, de 25 de agosto, de reforma Universitaria, (en adelante LRU) el régimen estatutario de dicho personal era el establecido para los funcionarios de organismos autónomos $^{1}$, por un lado, gracias a un pronunciamiento explícito de la norma, y por

${ }^{1}$ A este respecto téngase en cuenta el art. 5.1 del Real Decreto 543/1979, de 20 de febrero, sobre autonomía provisional económica y presupuestaria de las Universidades: "El nombramiento de personal de carrera del organismo se ajustara a lo dispuesto en el vigente estatuto de personal al servicio de los organismos autónomos, y sus 
otro, por ser la única realidad normativa en la que podrían tener cabida esta tipología de funcionarios. Tras la $\mathrm{LRU}^{2} \mathrm{y}$, sobre todo tras la promulgación de la Ley 30/1984, de 2 de agosto, de medidas para la Reforma de la Función pública, su régimen jurídico ha venido a complicarse extraordinariamente sin que, en la actualidad siga siendo claro, a pesar de la simpleza de algunas medidas legislativas o estatutarias, -algunas abiertamente contrarias a la vigente Ley Orgánica- cuál es el régimen jurídico que el legislador ha previsto para estos funcionarios.

La reforma Universitaria de 1983, centraba su actuación, sobre todo, en "establecer un marco para la renovación de la vida académica, pero lo decisivo en última instancia será la acción transformadora que emprendan las propias Universidades", atribuyendo un papel central al profesorado y los alumnos a los que se otorga la clave de "la nueva Universidad". Para ello, la ley se centra en "la creación de un estatuto propio y peculiar del funcionario docente". No parece, pues, que la reforma pretendiera afectar el régimen jurídico de los restantes funcionarios no docentes al servicio de las universidades públicas, para los que la LRU no pasaba a ser su primera norma reguladora con preferencia a la legislación general de funcionarios, y ello en la línea de lo que, tiempo atrás, se había establecido para los funcionarios de otros organismos autónomos a quienes, en primer término, "la relación jurídica existente entre estos funcionarios y los Organismos autónomos a los que sirven es de Derecho administrativo. Con carácter supletorio, les serán aplicables las normas relativas a los funcionarios de la Administración Civil del Estado ${ }^{3 "}$. Es decir, que el régimen jurídico regulador del personal funcionario propio de los OOAA pasaba en primer lugar por ser la norma especial constitutiva y reguladora del propio organismo autónomo, y, en segundo término, por el Estatuto del personal al servicio de los Organismos Autónomos.

Pero una cuestión más se añade a lo anterior, y es que la propia LRU tampo-

retribuciones, básicas y complementarias se regularan por la normativa del estatuto de personal aplicable a los funcionarios de organismos autónomos". La norma, por cierto, ni ha sido derogada formalmente ni se opone a la Ley 6/2001, de 21 de diciembre, Orgánica de Universidades en este apartado concreto de los recursos humanos destinados en la universidad.

${ }^{2}$ El art. 49.3 de la ya derogada Ley Orgánica 11/1983, de 25 de agosto, de reforma Universitaria, es idéntico al actual 73.3 de la Ley 6/2001, de 21 de diciembre, Orgánica de Universidades

${ }^{3}$ Art. 82.3 de la, ya derogada, Ley de 26 de diciembre de 1958, de Régimen Jurídico de las Entidades Estatales Autónomas. De igual forma el art. 1 del Decreto 2043/1971, de 23 de julio, por el que se aprueba el Estatuto del personal al servicio de los Organismos Autónomos, señala que el personal funcionario "se regirá por las disposiciones del presente Estatuto y por las normas especiales que sean de aplicación en virtud de lo dispuesto en el mismo" 
co determinaba cuál era la nueva naturaleza jurídica de las universidades públicas, a las que se describe lacónicamente como entidades dotadas de personalidad jurídica con un régimen de autonomía y de coordinación entre todas ellas. Tal vez la Ley dejó abierta la configuración jurídica de las universidades para una segunda etapa legislativa o bien a la acción normativa de los Estatutos universitarios que podrían delimitar su propia calificación como organismos públicos personificados ${ }^{4}$.

Tampoco aclara la cuestión del régimen jurídico de los funcionarios no docentes, la posterior Ley 30/1984, de 2 de agosto, de medidas para la reforma de la función pública, la cual supuso, en general, la equiparación del régimen jurídico de tanto de los funcionarios de la Administración Civil del Estado, como los de sus Organismos autónomos, y el mantenimiento de la peculiaridades para el personal docente e investigador, sanitario, de los servicios postales y de telecomunicación y del personal destinado en el extranjero ${ }^{5}$ ¿ ¿En dónde, pues, se encontraban encuadrados los funcionarios de administración y servicios de las Universidades públicas, dado que la propia Ley hace referencia a los funcionarios de la Administración Civil del Estado en sus diversas modalidades, a los de las CCAA $^{6}$ y de las administraciones locales ${ }^{7}$, sin que se realizara referencia alguna a aquéllos? ¿Tal vez este silencio denota su adscripción a alguna de las tres Administraciones tradicionales? La respuesta quizás pudiera venirnos tanto de la disposición adicional novena, dos, de la Ley 30/1984, en la que se dispone claramente: "sin perjuicio de lo previsto en el apartado tercero del artículo 27 de la presente Ley, se procede a la integración de Escalas de funcionarios de Organismos Autónomos

\footnotetext{
${ }^{4}$ Sobre esta cuestión, es interesante el estudio realizado por TARDIO PATO, J. A. "El derecho de las universidades públicas españolas". Vol. II Ed. PPU. Barcelona. Págs, 647-649. A pesar de lo señalado por la STS, contencioso sección 1, de 10 de mayo de 1988 (ROJ: STS 3502/1988) Recurso de apelación |Ponente: JUAN VENTURA FUENTES LOJO, que caracterizaba a las Universidades públicas como administraciones independientes que hacen de la nota de autonomía el eje de su régimen jurídico. La más reciente, STS, contencioso sección 2, de 24 de mayo de 2005 (ROJ: STS 3347/2005) No de Recurso: 2272/2000 | Ponente: RAFAEL FERNANDEZ MONTALVO, a la par de realizar una búsqueda jurisprudencial en la materia del régimen jurídico de las Universidad públicas, acaba por caracterizar a las Universidades como organismos autónomos singulares: "Pero, como hemos visto, no hay un sólo tipo de organismo autónomo, aplicándose también a las Universidades la idea de la representatividad y de singular autonomía para perfilar su naturaleza jurídica".

${ }^{5}$ Arts. 1.1 a) y 1.2 de la Ley 30/1984, de 2 de agosto, de medidas para la reforma de la función pública.

${ }^{6}$ Art. 11 "Las Comunidades Autónomas procederán a ordenar, mediante Ley de sus respectivas Asambleas Legislativas, su Función Pública propia. A estos efectos, y previa deliberación del Consejo Superior de la Función Pública, agruparán a sus funcionarios propios en los Cuerpos, Escalas, Clases y Categorías que proceda, respetando en todo caso los grupos establecidos en el artículo 25 de esta Ley.

${ }^{7}$ Art. 16 de la misma Ley.
} 
de la Administración del Estado, en la forma que a continuación se específica (...)" y entre la distintas escalas interdepartamentales aparecen las diferentes Escalas de funcionarios de administración y servicios de todas las Universidades públicas, conforme a su grupo de titulación. Como por otra disposición adicional, la décima, en la que se señalaba que la integración del personal funcionario de las Universidades en las Escalas de carácter interdepartamental, Técnica de Gestión, Administrativa, Auxiliar y Subalterna de los Organismos Autónomos respetando, en todo caso, lo establecido en el artículo 49 de la Ley Orgánica 11/1983, de 25 agosto, de Reforma Universitaria ${ }^{8}$. Disposición que, por un lado, viene a confirmar el carácter de funcionarios de OOAA de su personal de administración y servicios funcionario (en adelante PAS funcionario) y, por otro, dado el componente de autonomía de las mismas, identificar la singularidad de las Universidades en esta materia respecto del conjunto de organismos personificados creados por la Administración pública.

De ahí que del conjunto dispositivo de la Ley 30/1984, de 2 de agosto, se deduzcan claramente los siguientes extremos: primero, los funcionarios del personal de administración y servicios de las universidades públicas son equiparados a funcionarios de los organismos autónomos estatales. Segundo, las universidades, de esta manera y a estos solos efectos, son consideradas organismos autónomos, lo cual no quiere significar que efectivamente lo fueran en ese momento dado ya que a fecha de promulgación de la Ley, ya se encontraba en vigor la LRU ${ }^{9}$. Tercero, por tanto, dichos funcionarios tienen la condición de funcionarios de la Administración Civil del Esta-

8 “1. El personal de Administración y Servicios de las Universidades estará compuesto por funcionarios de la propia Universidad y por personal contratado. Asimismo, los funcionarios de otras Universidades, del Estado o de la Comunidad Autónoma podrán prestar servicios en cualquier Universidad en situación de supernumerario o en la que legalmente se establezca como equivalente. 2. El personal de Administración y Servicios de las Universidades será retribuido con cargo a los presupuestos de las mismas. 3. El personal de Administración y Servicios se regirá por la presente Ley y sus disposiciones de desarrollo, por la legislación de funcionarios que le sea de aplicación y, en su caso por las disposiciones de desarrollo de ésta que elaboren las Comunidades Autónomas y por los Estatutos de su Universidad. 4. Respecto a todos los funcionarios de Administración y Servicios, cualquiera que sea su Cuerpo o Escala, que desempeñen sus funciones en la Universidad, corresponderá al Rector de la misma adoptar las decisiones relativas a la situación administrativa y régimen disciplinario, a excepción de la separación del servicio que será acordada por el órgano competente según la legislación de funcionarios a propuesta del Consejo de Universidades".

${ }^{9}$ En aquel momento se suscito cierto debate acerca de la posible derogación del art. 49 de la LRU en lo que se opusiera a las disposiciones de la Ley 3/1984 de 2 de agosto, véase Gómez-Pantoja Cumplido, Joaquín (1999) "El régimen de la función pública aplicable al personal de administración y servicios de las Universidades: conciliación y aplicabilidad de las disposiciones estatales, Ley de Reforma Universitaria y Estatutos universitarios" en la obra "Las Universidades públicas y su régimen jurídico". Ed. Lex nova. Valladolid. Págs. 486 a 489. 
do, lo cual supone, de facto, la integración en escalas interdepartamentales operada en virtud de la propia Ley 30/1984, y, su consecuencia más inmediata, la incardinación de estos funcionarios dentro del art. 1.1 de la misma. Quinto, la integración de los funcionarios pertenecientes a las Escalas de funcionarios de administración y servicios de las universidades públicas en dichas escalas operaría automáticamente por el hecho de haber accedido, o se accediese, en un futuro a las mismas. Sexto, la integración en Escalas departamentales no excluye la posibilidad de que las Universidades sigan teniendo o ejerzan la posibilidad de seguir teniendo funcionarios de administración y servicios propios ${ }^{10}$. Es decir, por el hecho de su integración no se excluye la posibilidad de seguir "reclutando" funcionarios propios. Séptimo, en este último caso el régimen jurídico de ambos tipos de funcionarios, de las Escalas interdepartamentales y de las Escalas propias que subsistan es el mismo y, por tanto, su vinculación con la función pública estatal. Octavo, ambas normas adicionales de la Ley 30/1984, de 2 de agosto, tienen la continuidad en el tiempo de un norma con eficacia "ad futurum", constituyendo por sí mismas un régimen jurídico especial, insertado dentro del general, que ha de responder tan sólo en la peculiaridad prevista por su otra ley cabecera, la LRU. Por tanto, hablaríamos de un régimen legislativo bifásico. ${ }^{11}$

\section{EL PROCESO DE TRANSFERENCIAS A LAS COMUNIDA- DES AUTÓNOMAS EN MATERIA DE UNIVERSIDADES}

El traslado competencial de las materias de educación se inicia, en primer término, por los Estatutos de las denominadas Comunidades históricas, las transferencias realizadas a la Comunidad Valenciana y Canaria, y, posteriormente, las transferencias efectuadas, fruto de los Acuerdos Autonómicos de 28 de febrero de 1992. Para todos estos procesos, la fórmula empleada fue idéntica en su tenor literal: "Se transfiere la regulación y administración de la enseñanza en toda su extensión, niveles y grados, modalidades y especialidades en el ámbito de sus competencias, sin perjuicio de lo dispuesto en el artículo 27 de la Constitución y Leyes Orgánicas que, conforme al apartado 1, del artículo 81 de la misma, lo desarrollen; de las facultades que atribuye el Estado el número 30 del apartado 1, del artículo 149 de la Constitución y de la alta inspección necesaria para su cumplimiento y garantía".

10 Téngase en cuenta lo que establece el art. 3.2 e) de la Ley Orgánica 11/1983, de 25 agosto, de Reforma Universitaria, ya que la autonomía de las Universidades comprende necesariamente la selección, formación y promoción del personal docente e investigador y de administración y servicios, así como la determinación de las condiciones en que ha de desarrollar sus actividades

${ }^{11}$ Sobre la virtualidad de las disposiciones adicionales véase el "Acuerdo del Consejo de Ministros, de 22 de julio de 2005, por el que se aprueban las Directrices de técnica normativa" (BOE nº 180 de 29 de julio de 2005). 
Del proceso general traslativo, ha de señalarse la individualidad del traspaso competencial en materia de universidades que ha tenido una diferenciación clara respecto de los restantes niveles educativos, tanto por su individualidad institucional como por la singularidad de su personal. La clave de dichas particularidades se plasmó en los Reales Decretos de traspaso de servicios, dada la naturaleza de dichos instrumentos normativos, en los que necesariamente había de hacerse constar, entre otras cosas, las relaciones nominales del personal transferido, con expresión de su número de Registro de Personal -y además, en el caso de los funcionarios-', de su puesto de trabajo, situación administrativa y régimen de retribuciones. En el caso del personal contratado, las condiciones del contrato y régimen de retribuciones, y en el de personal laboral, su categoría, puesto de trabajo y régimen de retribuciones ${ }^{12}$. Del contenido general del conjunto de reales decretos de traspasos, y en relación con el personal funcionario de administración y servicios de las universidades públicas, no suponen una alteración, - a pesar de lo que pudiera suponerse-, en cuanto al régimen jurídico aplicable y el estatuto al que debían ajustarse dichos funcionarios. De esta manera el proceso de traslación jurídica de efectivos ofrece un tratamiento común en todos los procesos de transferencias.

\section{Universidades transferidas a las GG.AA "históricas ${ }^{13}$}

A las CCAA contempladas en las Disposición Transitoria $2^{\text {a }}$ de la Constitución Española, -País Vasco, Cataluña y Galicia- y $4^{\text {a }}$, Navarra, hemos de añadir la Comunidad Valenciana y Canaria, a través de las Leyes orgánicas de transferencias, como las primeras en asumir de forma material las competencias en materia de Universidades.

Como ya hemos apuntado, el conjunto de reales decretos plasmadores de la materialización del traspaso de servicios ${ }^{14}$ en materia de universidades a las Comunidades Autónomas mencionadas ${ }^{15}$, ofrecen un denominador común y es que el per-

${ }^{12}$ Art. 18.2 c) de la Ley 12/1983, de 14 de octubre, del Proceso autonómico.

${ }^{13}$ Éstas se realizaron a través de la Ley Orgánica 9/1992, de 23 de diciembre, de transferencia de competencia a las Comunidades Autónomas del art. 143 CE. Esta Ley obedece a los Acuerdos Autonómicos, el 28 de febrero de 1992, firmado por el Gobierno de la Nación, el PSOE y el PP. En el punto 2.1 se establecía que "la ampliación de competencias se llevará a cabo mediante la delegación o transferencia, acordada por las Cortes Generales según el procedimiento del Artículo 150.2 de la Constitución, plasmada en una ley orgánica en la que se incluyan, para todas las Comunidades Autónomas afectadas, todas las materias que son objeto de la ampliación". Una de cuyas materias eran las competencias de educación.

${ }^{14} \mathrm{Ha}$ de tenerse en cuenta que los Reales Decretos de transferencias "sólo pueden transferir servicios adecuados para ejercer las competencias (STC 77/1984, de 3 de julio)" que ni "atribuyen ni reconocen competencias, las 
sonal -en su terminología- no docente funcionario de las universidades públicas, no es objeto de traspaso, relacionándose conforme a la previsiones de la Ley del Proceso Autonómico tan sólo a los efectos de la determinación de los costes económico presupuestarios efectivos ${ }^{16}$. Medida que contrasta con el personal adscrito al Ministerio de Educación y Ciencia que sí es objeto de dicho traspaso a las distintas administraciones autonómicas. Navarra, a pesar de obtener las competencias plenas en la regulación y administración de la enseñanza en toda su extensión, niveles y grados, modalidades y especialidades, sin embargo no obtuvo traspasos materiales de bienes servicios y personal en materia de universidad por la sencilla razón de no existir universidad pública alguna en su ámbito territorial en el momento de ejecutar las transferencias $^{17}$.

cuales corresponden a las Comunidades Autónomas, con independencia y anterioridad de lo que se disponga en los Reales Decretos de transferencias, limitándose éstos a transferir los medios y servicios para su ejercicio, y únicamente se configuran como condición de pleno ejercicio de las competencias estatutariamente asumidas (STC 107/2001, de 23 de abril)". Es más, "no son en consecuencia normas determinantes del sistema constitucional de distribución de competencias, compuesto exclusivamente por la Constitución, los Estatutos y, en su caso, las demás disposiciones atributivas de competencias, cuyas prescripciones no pueden ser alteradas ni constreñidas por las disposiciones de los Decretos de traspasos; en este sentido las competencias son indisponibles por las Administraciones (STC 147/1998, de 2 de julio)". En este mismo sentido, la STS, Contencioso sección 7 del 29 de Enero del 2002 (ROJ: STS 503/2002) Recurso: 517/1998 |Ponente: FERNANDO MARTIN GONZALEZ.

${ }^{15} \mathrm{El}$ ámbito temporal de tales Reales Decretos, va desde el 6 de febrero de 1985 hasta el 30 de diciembre de 1987, algún tiempo después de la asunción de competencias en materia de educación en los Estatutos a los que hacen referencia: a) Real Decreto 305/1985, de 6 de febrero, sobre traspaso de servicios de la Administración del Estado a la Generalidad de Cataluña en materia de Universidades; b) Real Decreto 1014/1985, de 25 de mayo, sobre traspaso de funciones y servicios del Estado a la Comunidad Autónoma del País Vasco en materia de Universidades; c) Real Decreto 2633/1985, de 20 de noviembre sobre traspaso de servicios de la Administración del Estado a la Comunidad Valenciana en materia de Universidades; d) Real Decreto 1734/1986, de 13 de junio, sobre traspaso de servicios de la Administración del Estado a la Junta de Andalucía en materia de Universidades; e) Real Decreto 2802/1986, de 12 de diciembre, de traspaso de funciones y servicios a la Comunidad Autónoma de Canarias en materia de Universidades; e) Real Decreto 1754/1987, de 18 de diciembre, de traspaso a la Comunidad Autónoma de Galicia de los Servicios e Instituciones y medios personales materiales y presupuestarios en materia de Universidades.

${ }^{16}$ Por señalar el tenor literal de la forma dispositiva, que para todos es el mismo, señalaremos el Anexo I del Real Decreto 2633/1985, de 20 de noviembre sobre traspaso de servicios de la Administración del Estado a la Comunidad Valenciana en materia de Universidades: "F) Personal adscrito a los servicios e instituciones que se traspasan.1. Se transfiere a la Comunidad Autónoma en las condiciones señaladas en la legislación vigente, el personal del Ministerio de Educación y Ciencia y de sus Organismos Autónomos adscritos a los referidos servicios que se traspasan o, en su defecto, sus correspondientes dotaciones.2. En relación número 2 adjunta se recoge al personal no docente de las universidades que, no siendo objeto de traspaso, se relaciona a los efectos de la determinación de la subvención de la Comunidad Valencia a las Universidades"

${ }^{17}$ En efecto la primera universidad pública - y única hasta el momento-, el la Universidad pública de Navarra aprobada mediante Ley Foral de Navarra 8/1987, 21 abril, de creación de la Universidad Pública de Navarra («B.O.N.» 27 abril). 
De todos es conocido que los efectos de la transferencia de funcionarios a las CC. AA, es que pasan a depender de éstas orgánica y funcionalmente, integrándose como funcionarios propios de las mismas (lo cual implica la integración automática en los Cuerpos /Escalas de dichas administraciones ${ }^{18}$ ), la asunción de todas las obligaciones del Estado en relación con los mismos y el respeto de los derechos de cualquier orden que les correspondieran en el momento del traspaso. De esta manera, respecto a su Administración de origen estos funcionarios estatales transferidos a las Comunidades Autónomas, continuarían perteneciendo a sus Cuerpos o Escalas de origen, manteniendo los mismos derechos económicos, de carrera y profesionales que correspondieran a los funcionarios de dichos Cuerpos o Escalas en servicio activo $^{19}$. Pues bien, el proceso de transferencia de bienes y servicios de las distintas Universidades ubicadas en las Comunidades Autónomas mencionadas se completa sin que éste haya supuesto el traspaso real y efectivo de los funcionarios de administración y servicios de dichas universidades, lo cual viene a suponer que, de facto, sea la Administración General del Estado, la administración de vinculación para estos funcionarios y la realmente competente en todos los aspectos no expresamente reservados a los Rectores en la LRU, órgano administrativo que actúa en materia del estatuto del PAS funcionario, como órgano de funciones estatales.

${ }^{18}$ Así, por ejemplo en la Comunidad de Madrid, el Decreto 28/1987, de 23 de abril sobre integración en los correspondientes Cuerpos y Escalas de la Administración de la Comunidad de Madrid de los funcionarios propios de la misma que trae consecuencia de la disposición adicional primera de la Ley 1/1986, de 10 de abril, de la Función Pública de la Comunidad de Madrid, establece que son funcionarios propios de la Comunidad de Madrid los funcionarios de la Administración del Estado incursos en procesos de traspaso operados por Reales Decretos de transferencias. Véase por ejemplo la ORDEN de 4 de julio de 2014, del Consejero de Economía y Hacienda, por la que se procede a la integración individualizada de funcionarios propios de la Comunidad de Madrid en Cuerpos y Escalas de la misma (BOCM de 24 de julio de 2014), fruto de un proceso de transferencias de medios personales y materiales al servicio de la Administración de Justicia.

${ }^{19}$ Arts. 24 y 25 de la Ley 12/1983, de 14 de octubre, del Proceso autonómico. Sobre la igualdad de derechos económicos con los funcionarios de la Comunidad Autónoma y el momento en que ha de realizarse la equiparación, entre otras, véanse la STS, contencioso sección 7, de 8 de mayo de 2006 (ROJ: STS 2695/2006) $\mathrm{N}^{\circ}$ de Recurso: 3749/2000 |Ponente: PABLO MARIA LUCAS MURILLO DE LA CUEVA; y la STS, contencioso sección 7, de 14 de abril de 2008 (ROJ: STS 1681/2008) No de Recurso: 3749/2000 No de Recurso: 9797/2003 | Ponente: JOSE DIAZ DELGADO. Por otro lado, esta equiparación debe cohonestarse con la potestad de autoorganización de la Comunidad autónoma correspondiente: STS, contencioso sección 7, de 15 de octubre de 2007 (ROJ: STS 6788/2007) No de Recurso: 6655/2002 |Ponente: PABLO MARIA LUCAS MURILLO DE LA CUEVA y la STS, contencioso sección 3, de 26 de septiembre de 2000 (ROJ: STS 6765/2000) No de Recurso: 297/1999 |Ponente: OSCAR GONZALEZ GONZALEZ. 
La respuesta legislativa de las primeras autonomías a las que se traspasaron las universidades públicas de su territorio, respecto de esta tipología de funcionarios, no fue común. Se adelantó, a todas, la Comunidad Autónoma de Cataluña con su ley de función pública de $1985^{20}$, en la que se establece la inclusión plena del PAS funcionario de las universidades públicas, sin referencia alguna a la legislación estatal y con la única salvedad de respeto a la autonomía universitaria, lo cual no era sino una simple limitación en "clave interna" más que una típica cláusula de sistema normativo aplicable sobre funcionarios sometidos a regímenes jurídicos diversos. De hecho, la fórmula equivalía a integrarlos directamente en la función pública autonómica algo para lo que no estaba facultada la Generalidad en ese momento. En cambio, la fórmula diseñada por la Ley de función pública de la Comunidad Autónoma del País Vasco pasaba por respetar en su integridad el art. 49 LRU, su sistema de fuentes aplicable, y finalmente diferenciar al PAS funcionario al modo en que lo estaban otras instituciones formalmente vinculadas a la Comunidad (Tribunal Vasco de Guentas Públicas, Consejo de Relaciones Laborales... $)^{21}$. Lo cual no suponía su integración automática en la función pública de la Administración pública vasca. Por su parte, las Leyes de función pública de la Comunidad Gallega ${ }^{22}$, Canaria ${ }^{23}$ y Valenciana ${ }^{24}$, omitían cualquier referencia a los funcionarios del PAS de las Universidades transferidas. Esta misma carencia dispositiva se reproduce en la legislación sectorial autonómica relativa a las universidades públicas de su entorno hasta que, finalmente, a la entrada en vigor de la nueva Ley Orgánica de Universidades de 2001, se ha dado cabida a algunas disposiciones en las que se ha aludido más o menos expresamente al PAS funcionario.

${ }^{20} \mathrm{El}$ art. 2.2. b) de la anterior Ley 17/1985, de 23 de julio, de la Función Pública de la Administración de la Generalidad de Cataluña (Vigente hasta el 23 de Noviembre de 1997), incluía dentro de su ámbito de aplicación "al personal de las universidades, respetando la autonomía universitaria"

${ }^{21} \mathrm{El}$ art. 2.1 e) de la vigente Ley 6/1989, de 6 de julio, de la Función Pública Vasca, establece la aplicación de la Ley: "La presente ley es de aplicación al personal al servicio de: la Universidad del País Vasco, conforme a las previsiones contenidas en la Ley Orgánica 11/1983, de 25 de agosto, de Reforma Universitaria y ello sin perjuicio del respeto a la autonomía universitaria".

${ }^{22}$ Ley 4/1988, de 26 de mayo, de la Función Pública de Galicia. (Vigente hasta el 14 de junio de 2008).

${ }^{23}$ Ley 2/1987, de 30 de marzo, de la Función Pública Canaria, (aún vigente).

${ }^{24}$ Tanto la Ley 10/1985, de 31 de julio, de la Función Pública Valenciana (derogada), como el Decreto Legislativo de 20 de marzo de 1991, de la Generalidad Valenciana, por el que se aprueba el Texto Refundido de la Ley de la Función Pública Valenciana, (actualmente derogado) no hacía mención alguna al personal funcionario de las universidades públicas. 
Esta carencia legislativa hubiera podido ser suplida por los primeros Estatutos de las Universidades públicas, precisamente aprobados por los respectivos Órganos ejecutivos superiores aunque, con reproducciones más o menos literales de la LRU en relación con el régimen jurídico regulador del PAS funcionario, tampoco contribuyeron a establecer el contenido real del régimen estatutario de dichos funcionarios, simplificando en exceso incluso su régimen jurídico y sus sistema fuentes cuando se hubiera esperado una mayor clarificación de sus estatuto, dada la posición que la LRU daba a los Estatutos universitarios. Así, por ejemplo, los Estatutos de la Universidad Autónoma de Barcelona señalaban que el personal de administración y servicios funcionario de la Universidad Autónoma de Barcelona se regía por las normas dictadas por el Estado y por la Generalidad en el ámbito de sus competencias, por los Estatutos de la Universidad y sus normas de desarrollo ${ }^{25}$; o también con la alusión a la autonomía universitaria como fuente reguladora en el caso de los Estatutos de la Universidad de Las Palmas de Gran Canaria ${ }^{26}$, Alicante $^{27}$ y del País Vas$\mathrm{co}^{28}$. Con más indefinición, si cabe, encontramos los Estatutos de la Universidad Jaume I al señalar en una tautología clara, que el PAS "se ha de regir por la legislación de funcionarios", o los de la Universidad de Valencia "Estudio General" para los que el PAS se rige por "la legislación vigente que le sean aplicables y por estos estatutos"; a los que se añadían los de la Universidad de Sevilla al establecer que el PAS funcionario se regía por la legislación universitaria, por la legislación de funcionarios y por sus estatutos $^{29}$

\footnotetext{
${ }^{25}$ Art. 153.2 Decreto 37/1985, de 18 de enero, por el que se aprueban los Estatutos de la Universidad Autónoma de Barcelona (actualmente derogados).

${ }^{26}$ Art. 191.5 del Decreto 94/1991, de 29 de abril, por el que se aprueban los Estatutos de la Universidad de Las Palmas de Gran Canaria (hoy derogado pero que se ha transmitido en su mismo tenor literal tras diversas modificaciones hasta los actuales Estatutos). Los de la Universidad de La Laguna aprobados por Decreto 192/1985, de 13 de junio, en su el art. 42.2, establecen como su régimen jurídico la legislación universitaria y por la de los funcionarios públicos que le sea de aplicación. Lo cual supone otra nueva indefinición.

${ }^{27}$ Art. 159 de los Estatutos de la Universidad de Alicante aprobados por el Decreto 107/1985, de 22 de julio.

${ }^{28}$ Art. 136.3 del Decreto 70/1985, de 18 de Marzo

${ }^{29}$ Art. 181 de los Estatutos de la Universidad de Sevilla aprobados mediante Decreto 148/1988 de 5 de abril (ya derogados). En cambio, el art. 113 de los actuales Estatutos (Decreto 3234/2003, de 25 de noviembre), bajo la rúbrica "Régimen jurídico", da con la clave del régimen estatutario de los funcionarios del PAS: "El personal funcionario de administración y servicios se regirá por la Ley Orgánica de Universidades y sus normas de desarrollo, por la legislación de función pública del Estado y de la Comunidad Autónoma de Andalucía, así como por el presente Estatuto, el Reglamento general del personal de administración y servicios y las disposiciones que lo desarrollen".
} 
Por tanto, el panorama regulador del Estatuto de los funcionarios del PAS de las Universidades públicas no encontró una aclaración por parte autonómica de su régimen jurídico, salvo el caso de la Comunidad Autónoma de Cataluña aunque yendo más allá de lo que la LRU había establecido como sistema normativo de aquéllos, al anteponer, de facto, la normativa autonómica de función pública a la Estatal. La escasez legislativa se fue sustituyendo, de facto, por una atracción paulatina al ámbito de la Administración autonómica de estos funcionarios.

\section{Universidades transferidas a las Comunidades Autóno- mas que accedieron a la autonomía por la vía del artículo 143 de la Constitución}

El proceso de transferencias cuyo punto de inicio tiene los ya mencionados Acuerdos Autonómicos de 28 de febrero de 1992, y que, tras la promulgación de la Ley Orgánica 9/1992, de 23 de diciembre, de transferencia de competencia a las Comunidades Autónomas del artículo 143 CE, y su incorporación a los diversos Estatutos, se concretó en sendos Decretos aprobados dentro del curso de los años 1995 y 1996. Las transferencias afectaban a las Comunidades Autónomas de Castilla León y la Mancha, Extremadura, la Comunidad de Madrid, Asturias, Cantabria, Región de Murcia, Aragón, la Rioja e Illes Balears ${ }^{30}$. Todos los Reales Decretos ofrecen un cuerpo común con ligeras variaciones entre sí, aunque significativas respecto de los

${ }^{30}$ La relación de Decretos son los que a continuación se relacionan: el Real Decreto 848/1995, de 30 de mayo, sobre traspaso de funciones y servicios de la Administración del Estado al Principado de Asturias en materia de Universidades. (B.O.E. 07-07-1995), el Real Decreto 1382/1996, de 7 de junio, sobre traspaso de funciones y servicios de la Administración del Estado a la Comunidad Autónoma de Cantabria en materia de Universidades. (B.O.E. 28-06-1996), el Real Decreto 95/1996, de 26 de enero, sobre traspaso de funciones y servicios de la Administración del Estado a la Comunidad Autónoma de La Rioja en materia de Universidades. (B.O.E. 22-02-1996 \# Corrección de errores B.O.E. 26-03-1996), el Real Decreto 948/1995, de 9 de junio, sobre traspaso de funciones y servicios de la Administración del Estado a la Comunidad Autónoma de la Región de Murcia en materia de Universidades (B.O.E. 07-071995), el Real Decreto 96/1996, de 26 de enero, sobre traspaso de funciones y servicios de la Administración del Estado a la Comunidad Autónoma de Aragón en materia de Universidades. (B.O.E. 21-021996), el Real Decreto 324/1996, de 23 de febrero, sobre traspaso de funciones y servicios de la Administración del Estado a la Comunidad Autónoma de Castilla-La Mancha en materia de Universidades. (B.O.E. 21-03-1996), el Real Decreto 634/1995, de 21 de abril, sobre traspaso de funciones y servicios de la Administración del Estado a la Comunidad Autónoma de Extremadura en materia de Universidades. (B.O.E. 17-05-1995), el Real Decreto 2243/1996, de 18 de octubre, sobre traspaso de funciones y servicios de la Administración del Estado a la Comunidad Autónoma de las Islas aleares en materia de Universidades (B.O.E. 08-11-1996 \# Corrección de errores B.O.E. 19-11-1996), el Real Decreto 942/1995, de 9 de junio, sobre traspaso de funciones y servicios de la Administración del Estado a la Comunidad de 
Decretos comentados en el apartado anterior. En los mismos, se hace una referencia genérica a las funciones y competencias que se transfieren, que, en materia de enseñanza superior, son las atribuidas a las Comunidades Autónomas por la Ley Orgánica 11/1983, de 25 de agosto, de Reforma Universitaria, y que vienen a concretarse en: a) la creación, supresión, adscripción e integración, según corresponda, de Facultades, Escuelas Técnicas Superiores, Escuelas Universitarias, Institutos Universitarios, Colegios Universitarios, así como aquellos otros centros universitarios cuya creación no corresponda a la Universidad.; b) la gestión, de acuerdo con los criterios establecidos por la Administración del Estado, de las becas y ayudas al estudio universitario correspondientes a las convocatorias del Ministerio de Educación y Ciencia y c) la gestión de las exenciones parciales o totales del pago de las tasas académicas acordadas por el Estado.

Respecto al capítulo de transferencias de personal de las Universidades, se produce un cambio significativo, dado que todos los Decretos señalan que "no existen medios personales propios de la Admón. del Estado objeto de traspaso". Hecho que se "redondea" con el Real Decreto de traspaso en la Comunidad de Madrid, el Real Decreto 942/1995, de 9 de junio, en el que, teóricamente, se produce un traspaso personal adscrito a al Administración General del Estado y que correspondía a funcionarios pertenecientes al organismo autónomo "Junta de Construcciones, Instalaciones y Equipamiento Escolar" cuya sede se situaba en la ciudad de Madrid. Esta redacción no se corresponde con los anteriores decretos de traspaso, cuyo literal era: "en la relación, número 2, se recoge el personal no docente de la Universidad, que, no siendo objeto de traspaso, se relaciona a los efectos oportunos". Primera consecuencia es que nos encontraríamos con personal de la AGE y que a los efectos oportunos, reflejarían las consignaciones presupuestarias relativas a su coste, desglosado entre retribuciones básicas y complementarias. Pero ¿cómo pueden interpretarse lo Decretos de transferencias en relación con el PAS funcionario? ¿A qué Administración territorial quedaban vinculados los funcionarios del PAS de las Universidades transferidas en esta segunda oleada? La respuesta no es fácil, y teniendo en cuenta el repetido art. 49.3 $\mathrm{LRU}^{31}$, nuevamente acudiremos a la legislación autonómica de función pública de las Comunidades Autónomas receptoras, para comprobar si realmente podemos encontrar alguna refe-

\footnotetext{
Madrid en materia de Universidades. (B.O.E. 22-06-1995) y Real Decreto 907/1995, de 2 de junio, sobre traspaso de funciones y servicios de la Administración del Estado a la Comunidad de Castilla y León en materia de Universidades (B.O.E. 01-08-1995).

31 "El personal de Administración y Servicios se regirá por la presente Ley y sus disposiciones de desarrollo, por la legislación de funcionarios que le sea de aplicación y, en su caso por las disposiciones de desarrollo de ésta que elaboren las Comunidades Autónomas y por los Estatutos de su Universidad".
} 
rencia legislativa sobre aquéllos funcionarios y su supuesta integración en la función pública autonómica. De las diez CCAA, afectadas por la transferencia competencial, y sus respectivas Leyes de Función pública, en seis de ellas (Madrid, Cantabria, Asturias, La Rioja, Aragón y Murcia) no encontramos referencia directa alguna. Tan sólo podríamos interpretar incluido al PAS funcionario de las Universidades, en dos de dichas CCAA, en normas con el siguiente tenor literal: "El ámbito de aplicación de esta Ley se extiende a todo el personal al servicio de la Administración de la Comunidad Autónoma de la Rioja y de los Organismos dependientes de la misma, que perciban sus retribuciones con cargo a las correspondientes consignaciones presupuestarias" $32 "$ o "a los efectos de esta Ley, por Administración Pública de la Región de Murcia deberá entenderse tanto su Administración Central o directa como las fundaciones públicas, Organismos Autónomos y otras Entidades públicas constitutivas de su Administración funcionalmente descentralizada ${ }^{339}$.

Sin embargo, las Leyes de función pública de las Comunidades de Castilla La Mancha, Castilla León y Extremadura, tras la promulgación de la Ley Orgánica 6/2001, de 21 de diciembre, de Universidades, han dado entrada dentro de su ámbito de aplicación a los funcionarios del PAS, bien sin matización alguna: "la presente Ley se aplica al personal funcionario y, en lo que proceda, al personal laboral y al personal eventual de las siguientes Administraciones Públicas, Entidades, Organismos o Instituciones: c) La Universidad de Extremadura, en relación a su personal de administración y servicios ${ }^{34}$, bien con el filtro de la legislación sectorial de universidades: "Esta Ley se aplica al personal funcionario y, en lo que proceda, al personal laboral y al personal eventual al servicio de alguna de las siguientes Administraciones públicas, entidades, organismos o instituciones: d) Las universidades públicas de Castilla-La Mancha, en los términos previstos por la legislación en materia de universidades, sin perjuicio del respeto a la autonomía universitaria ${ }^{35}$ ". O bien, con otra más fórmula más acorde con la redacción del art. 73.3 de la Ley Orgánica 6/2001, de 21 de diciembre, de Universidades ${ }^{36}$ : "Los preceptos de la presente Ley serán de aplicación al personal docente no uni-

32 Art. 2.2 de la Ley 3/1990, de 29 de junio, de Función Pública de la Administración Pública de la Comunidad Autónoma de la Rioja

${ }^{33}$ Es el art. 2.2 del Decreto Legislativo 1/2001, de 26 de enero, por el que se aprueba el Texto Refundido de la Ley de la Función Pública de la Región de Murcia

${ }^{34}$ Art. 3.1 c) de la reciente Ley 13/2015, de 8 de abril, de Función Pública de Extremadura.

35 Art. 2.1 d) de la Ley 4/2011, de 10 de marzo, del Empleo Público de Castilla-La Mancha.

36 "El personal funcionario de administración y servicios se regirá por la presente Ley y sus disposiciones de desarrollo, por la legislación general de funcionarios, y por las disposiciones de desarrollo de ésta que elaboren las Comunidades Autónomas, y por los Estatutos de su Universidad". 
versitario en aquellas materias que no se encuentren reguladas por la normativa básica y específica que la desarrolla 37 ". Todo lo cual viene a señalarnos que las ligeras modificaciones legislativas operadas por la segunda Ley Orgánica de Universidades y, sobre todo, por la realidad de los hechos - la vinculación de las Universidades a la respectiva Comunidad Autónoma- han producido una cierta traslación en el estatuto específico del PAS funcionario de las Universidades públicas hacia su "comunitarización". Debe advertirse, no obstante, que Ley Orgánica tampoco supuso un cambio sustancial en el sistema de fuentes regulador de dichos funcionarios en el aspecto formal, tal y como veremos más adelante. Quizás la Ley plantea o señala, más bien, un camino sobre el que comenzar a transitar.

El resultado de esta acción legislativa se añade al que hemos analizado en el anterior punto respecto de las Autonomías de recepción más temprana de las Universidades transferidas, lo que arroja una cada vez mayor singularización de estos funcionarios de tal manera que su adscripción al modelo de función pública tradicional propio de las Administraciones territoriales no parece muy claro ¿Son funcionarios autonómicos, estatales o simplemente funcionarios de las Universidades?

\section{LEGISLAGIÓN ESTATAL DE DESARROLLO DE APLICA- CIÓN DIREGTA AL PAS FUNGIONARIO DE LAS UNIVER- SIDADES PÚBLICAS.}

Tras la entrada en vigor de la LRU y la Ley 30/1984, de 2 de agosto, la AGE dedicaba, en exclusiva, al PAS funcionario de las Universidades públicas un reglamento, en desarrollo de esta última y de las previsiones de la disposición final segunda de la Ley 21/1986, de 23 de diciembre, de Presupuestos Generales del Estado para 1987. La Ley instaba al Gobierno a la adecuación de las retribuciones complementarias de los funcionarios no docentes de las Universidades dentro del marco del nuevo sistema retributivo establecido en la Ley 30/1984, de 2 de agosto, de Medidas para la Reforma de la Función Pública. El fruto de dicho mandato legislativo fue el Real Decreto 1545/1987, de 11 de diciembre, por el que se establecía el régimen de retribuciones de los funcionarios de Administración y Servicios de las Universidades de competencia de la Administración del Estado ${ }^{38}$. El reglamento, se dictó a pro-

\footnotetext{
${ }^{37}$ Art. 2.2 de la Ley 7/2005, de 24 de mayo, de la Función Pública de Castilla y León.

${ }^{38} \mathrm{El}$ Decreto con indudable fuerza normativa no ha sido derogado y tampoco se opone a la Ley Orgánica 6/2001, de Universidades.
} 
puesta conjunta de los Ministerios para las Administraciones Públicas y de Economía y Hacienda, y a iniciativa del de Educación y Ciencia, lo cual no hace sino reafirmar la inclusión de los funcionarios de administración y servicios de las universidades públicas dentro del régimen jurídico general establecido para los funcionarios de la AGE. Ha de tenerse en cuenta que las Universidades, en esa fecha, ya gozaban del régimen de autonomía universitaria que les otorgaba la LRU precisamente en relación con su personal funcionario no docente. Más revelador de la ya mencionada inclusión en el régimen general estatutario, nos parece precisamente la afirmación del Real Decreto 1545/1987, cuando establece, de forma clara, que los funcionarios de Administración y Servicios de las Universidades de competencia de la Administración del Estado, a los que se refiere el mismo artículo del Real Decreto, les era de plena aplicación las normas que, sobre el régimen de retribuciones, se dicten, con carácter general para los funcionarios de la Administración del Estado ${ }^{39}$. Así pues, el personal funcionario no docente (PAS) no era sino personal funcionario de la Administración General del Estado cuya única singularidad venía dada por el art. 49 de la LRU, es decir, su régimen de situaciones administrativas, régimen disciplinario que no supusiera separación del servicio- y la atribución "ex lege" de seleccionar a dichos funcionarios, para las que se preveía la actuación exclusiva del Rector, en detrimento de la Dirección General de la Función Pública de la Administración General del Estado. Además debe tenerse en cuenta que el reglamento retributivo al que hemos hecho alusión no procede del desarrollo de la LRU, sino de las disposiciones de la Ley 30/1984, de 2 de agosto, a la sazón la norma de referencia de la función pública estatal.

De aquí que, como hemos enunciado, sugieran más interrogantes que luces sobre el nuevo régimen jurídico inaugurado por la LRU y la Ley 30/1984, de 2 de agosto, y que lejos de despejarse en las sucesivas reformas legislativas sobre Universidades, se han mantenido -e incluso aumentado- dichas incertidumbres jurídicas. ¿Podemos afirmar que tras ambas leyes y las disposiciones normativas comentadas, los funcionarios de administración y servicios de las universidades públicas son funcionarios estatales?

La realidad expuesta sobre el "no traspaso" de los funcionarios del PAS de las universidades tanto en los de primera generación, como de las que, por entonces,

39 Disposición Adicional $1^{\text {a }}$ del Real Decreto 1545/1987, de 11 de diciembre, por el que se establece el régimen de retribuciones de los funcionarios de Administración y Servicios de las Universidades de competencia de la Administración del Estado (BOE nº 301, de 17/12/1987). 
eran Universidades de la Administración General del Estado (vinculadas, por tanto, al Ministerio de Educación y Ciencia) se traduce en su inclusión dentro del ámbito de aplicación de algunas normas generales de gestión de los Cuerpos y Escalas funcionarios de la Administración General del Estado. Así, por ejemplo, el aún en vigor, Real Decreto 2169/1984, de 28 de noviembre, de atribución de competencias en materia de personal, en desarrollo de la Ley 30/1984, de 2 de agosto, de medidas para la reforma de la función pública ${ }^{40}$, establecía que las competencias respecto del personal universitario y del personal de administración y servicios de las Universidades serían ejercidas, en todo caso, de acuerdo con lo previsto en la Ley Orgánica 11/1983, de 25 de agosto, de Reforma Universitaria, instando al Ministro de Educación y Ciencia para elevar al Gobierno las disposiciones de desarrollo de la disposición adicional $15^{\text {a }}$ de la Ley de Medidas para la Reforma de la Función Pública ${ }^{41}$. Debemos reseñar que el reglamento se refiere a las competencias en materia de administración del personal de la AGE, incluido dentro del artículo 1 de la Ley 30/1984, de 2 de agosto.

O también, el ya derogado Reglamento General de provisión de puestos de trabajo y de promoción profesional de los funcionarios de la Administración del Esta$\mathrm{do}^{42}$, cuando en su disposición adicional $7^{\mathrm{a}}$, determinaba la aplicación explícita del Reglamento, al personal funcionario de administración y servicios de las universidades en todo aquello que no estuviera atribuido expresamente a los estatutos de las mismas por el articulo 50 de la Ley 11/1983, de 25 de agosto, de reforma universitaria. Es decir, una particularidad fruto del carácter especial de las Universidades, en el ejercicio de su autonomía, y que la disposición legislativa otorgaba a los Estatutos, los cuales, debían establecer normas para asegurar la provisión de las vacantes que se produjeran, la selección según los principios de publicidad, igualdad capacidad y mérito, y el perfeccionamiento y promoción profesional del personal. Y que en caso de no ser así, el Reglamento ofrecía su supletoriedad, para todos o algunos de los extremos mencionados por la LRU, respecto del personal funcionario de administración y servicios de aquellas universidades que no hayan desarrollado dichas materias en sus Estatutos reguladores, todo ello, en el marco de lo establecido en la ley 30/1984, de 2 de agosto, de medidas para la reforma de la función pública. El actual Reglamento, en vigor desde $1995^{43}$, en cambio, opta por una cláusula de supletoriedad ge-

\footnotetext{
${ }^{40}$ (BOE de 7 de diciembre de 1984)

41 Disposición adicional $3^{\mathrm{a}}$.

42 Aprobado por el Real Decreto 2617/1985, de 9 de diciembre.

${ }^{43}$ Se trata del Real Decreto 364/1995 de 10 de marzo, por el que se aprueba el Reglamento Ge-
} 
neral: "Este Reglamento tendrá carácter supletorio para todos los funcionarios civiles al servicio de la Administración del Estado no incluidos en su ámbito de aplicación y los de las restantes Administraciones públicas", que afecta tanto al personal que no sea funcionario perteneciente a Cuerpos y Escalas propias de la Administración General del Estado y sus Organismos autónomos pero que se encuentre dentro del ámbito de la misma como, en su caso, a funcionarios de Cuerpos y Escala de otras Administraciones territoriales (Comunidades autónomas y Administración local). Entendemos que el normador estatal no hace una referencia explícita al PAS funcionario de las universidades públicas - en contraposición con al anterior normativa sobre la cuestión y otra que citaremos-porque dicha regulación entraba de lleno dentro de las facultades de la autonomía universitaria la cual comprende explícitamente "la selección, formación y promoción del personal docente e investigador y de administración y servicios, así como la determinación de las condiciones en que ha de desarrollar sus actividades ${ }^{44}$ ". Ahora bien las facultades de regulación de estas materias no supone apartar a dichos funcionarios de su vinculación con la normativa estatal de función pública más allá de la que tenga un carácter básico y de los órganos que pueden ejercerla.

De igual forma, el Real Decreto 365/1995, de 10 de marzo, por el que se aprueba el Reglamento de situaciones administrativas de los funcionarios civiles de la Administración General del Estado, incluye un pronunciamiento expreso respecto de los funcionarios de administración y servicios, al señalar que corresponden al Rector, la competencia en materia de situaciones administrativas tanto de los funcionarios docentes que desempeñen sus funciones en las Universidades, como de los pertenecientes a Escalas de Administración y Servicios propias de las mismas ${ }^{45}$. El hecho es significativo porque el Reglamento tan sólo es aplicable a los funcionarios de la Administración General del Estado y sus Organismos autónomos comprendidos en el ámbito de aplicación de la Ley 30/1984, de 2 de agosto, de Medidas para la Reforma de la Función Pública, sin que se disponga cláusula supletoria alguna respecto de los funcionarios de las restantes Administraciones públicas. Reglamento que obviamente sería de aplicación indiscutida al PAS funcionario.

neral de ingreso del personal al servicio de la Administración General del Estado y de provisión de puestos de trabajo y promoción profesional de los funcionarios civiles de la Administración General del Estado.

${ }^{44}$ Art. 3.2 e) de la Ley Orgánica 11/1983, de 25 de agosto, Orgánica de Universidades. Tenor literal que se reproduce en el art. 2.2 e) de la vigente Ley Orgánica 6/2001, de 21 de diciembre, de Universidades.

${ }^{45}$ Es la disposición adicional 4 . 
El supuesto anterior viene a matizarse con Real Decreto 33/1986, de 10 de enero, por el que se aprueba el Reglamento del régimen disciplinario de los funcionarios de la Administración del Estado, en el que se establece la aplicación directa al personal funcionario comprendido en el artículo 1.1 de la Ley 30/1984, de 2 de agosto, de Medidas para la Reforma de la Función Pública y supletoria para los demás funcionarios al servicio del Estado y de las Administraciones Públicas no incluidos en su ámbito de aplicación ¿En qué lugar quedarían los funcionarios del PAS de las Universidades, suponiendo que estuvieran incluidos en un égimen de aplicación directa? La respuesta la aporta la disposición adicional $2^{\mathrm{a}}$, que viene a incluirlos directamente al régimen de aplicación directa, al señalar que, de acuerdo con lo dispuesto en los artículos 44 y 49 de la Ley 11/1984, de 25 de agosto, de Reforma Universitaria, la competencia para la incoación y resolución de expedientes disciplinarios al profesorado y personal de Administración y Servicios de las Universidades corresponderá a los Rectores, con excepción de la separación del servicio, que será acordada por el Consejo de Ministros ${ }^{46}$. Por tanto, el régimen disciplinario aplicable es el propio de los funcionarios comprendidos en el artículo 1.1 de la Ley 30/1984, de 2 de agosto, de Medidas para la Reforma de la Función Pública, con la única salvedad de la autoridad administrativa encargada de la incoación y resolución que viene a compatibilizar la norma con el régimen de autonomía universitaria de las Universidades públicas.

La Ley 30/1984, en su art. 13 -aun vigente-, establecía la creación de un Registro Central en el que se debía inscribir a todo el personal al servicio de la Administración del Estado, y en el que sería objeto de anotación preceptiva todos los actos que afecten a la vida administrativa del mismo. Así pues, la norma es clara y expresa en cuanto a su ámbito de aplicación. Y como no podía ser de otra forma también afecta al PAS funcionario. Tras una aplicación directa al PAS funcionario de las Universidades públicas del Real Decreto 1405/1986, de 6 de junio, que aprobaba el Reglamento del Registro Central de Personal, su modificación realizada en $1999^{47}$ viene a singularizar el caso de las Universidades públicas, todas formalmente transferidas en aquella fecha. En efecto, la reforma del Reglamento viene a diferenciar, a los efectos de su inscripción obligatoria en el Registro Central de Personal, a los funcionarios pertenecientes a los Cuerpos Docentes Universitarios regulados por el Estado, en

${ }^{46} \mathrm{El}$ art. 49.4 señalaba que "a propuesta del Consejo de Universidades"

${ }^{47}$ A través del Real Decreto 2073/1999, de 30 de diciembre, por el que se modifica el Reglamento del Registro Central de Personal y las normas de coordinación con los de las restantes Administraciones públicas. 
tanto no se constituya el Registro de Personal específico al que hace referencia el artículo 42 de la Ley Orgánica 11/1983, de 25 de agosto, de Reforma Universitaria $^{48}$ y el PAS funcionario, determinando la aplicación operativa de las inscripciones -desde 1986 su inscripción era obligatoria- en el Registro Central de Personal a la suscripción de convenios, a tal efecto, entre el Ministerio de Administraciones Públicas y la Administración de que se trate ${ }^{49}$. En estos convenios se especificaría el régimen regulador de las inscripciones y anotaciones, los actos administrativos, resoluciones y datos que deberían ser objeto de anotación ${ }^{50}$ respecto de los funcionarios afectados. En el campo específico de nuestro estudio, el PAS funcionario, en virtud precisamente del Convenio entre el órgano competente de la AGE y la conferencia de Rectores y, de forma específica también para el personal docente de las universidades, se dictó la Resolución de 5 de noviembre de 2012, de la Secretaría de Estado de Administraciones Públicas ${ }^{51}$, por la que continuaría siendo objeto de aplicación de las normas relativas al Reglamento del Registro Central de Personal ${ }^{52}$.

Vistas las disposiciones normativas expuestas, cuyo ámbito de aplicación tiene por objeto a los funcionarios de la AGE incluidos dentro del artículo 1.1 de la Ley 30/1984 de 2 de agosto, poco sentido tendrían las singularidades descritas para el PAS funcionario, dentro de las generales, si el personal al que se refieren, no estuviera incluido dentro de su ámbito de aplicación. Entendemos más bien que el resultado de dicha especificidad viene dado, en virtud de las peculiaridades que la Ley atribuye a las Universidades (las cuales están llamadas de manera indisoluble a la

\footnotetext{
${ }^{48} \mathrm{El}$ art. 42 señalaba que "Las Comisiones a que hacen referencia los artículos 35 y 39 de la presente Ley, propondrán, mediante informe motivado, el nombramiento de candidatos, que en ningún caso podrán exceder al número de plazas convocadas. Dichos nombramientos serán efectuados por el Rector de la Universidad correspondiente, comunicados al Consejo de Universidades a efectos de su inscripción en el Registro de Personal de los Cuerpos respectivos y publicados en el «Boletín Oficial del Estado»

${ }^{49}$ Esta previsión normativa se ha traducido en el Convenio Marco de Colaboración entre el Ministerio de Política Territorial y Administración Pública y la Conferencia de Rectores de las Universidades Españolas (CRUE), firmado con fecha 30 de junio de 2011.

${ }^{50}$ Art. 5.2, dentro de la rúbrica dedicada al “Ámbito registral", del Real Decreto 2073/1999, de 30 de diciembre, por el que se modifica el Reglamento del Registro Central de Personal y las normas de coordinación con los de las restantes Administraciones públicas.

${ }^{51}$ BOE n. ${ }^{\circ} 302$ de 17 de diciembre de 2012.

52 Normas que, a su vez, han sido desarrolladas por la Resolución de 2 de septiembre de 2002, de la Secretaría de Estado para la Administración Pública, por la que se establecen los nuevos modelos de documentos para la inscripción y anotación en el Registro Central de Personal de diversos actos administrativos de personal y nuevos modelos de títulos administrativos y hojas de servicio del personal funcionario y laboral al servicio de la Administración General del Estado (BOE n 227 del 21 septiembre 2002). Esta Resolución es el texto básico que ha sufrido algunas modificaciones parciales.
} 
prestación del servicio público de la educación superior) más que a una exclusión del régimen jurídico general de la función pública estatal para aquéllos. Realmente, y lo repetimos, poco sentido tendría su alusión específica en normas reguladoras de la función pública estatal -más allá del régimen de supletoriedad- si realmente no estuvieran incluidos dentro del ámbito general de la función pública estatal, en contraposición con la función pública autonómica. De todas formas, he aquí la principal disyuntiva para estos funcionarios y es, si poseen un régimen estatutario propio, singular, en contraposición con el estatuto de los funcionarios de la AGE, de los de las CG.AA o de la Administración local, o bien, dentro de éstas funciones públicas territoriales, pudieran estar comprendidos en un régimen estatutario propio y específico, a la manera de otros también específicos de determinados funcionarios adscritos a una prestación y servicio público determinado (Cuerpos docentes, sanitarios, policiales....) pero siempre dentro de un ámbito estatutario general de los funcionarios de la AGE. Nosotros nos inclinamos por esta última posibilidad de poseer un estatuto propio y peculiar de incardinación estatal.

\section{LA LEY ORGÁNICA 6/2001, DE 21 DE DICIEMBRE, DE UNIVERSIDADES Y EL RÉGIMEN ESTATUARIO DEL PAS FUNCIONARIO DE LAS UNIVERSIDADES PÚBLICAS.}

El tenor literal del artículo de la nueva Ley Orgánica, encargado de establecer el régimen jurídico del PAS funcionario, parecía no tener diferencias sustanciales con el anterior art. 49 de la LRU, pero una comparación entrambos parece señalarnos que la nueva Ley tiende a posicionar a los funcionarios del PAS en un escalón más dentro del ámbito de acción de las Comunidades Autónomas. Algo que, según hemos señalado más arriba, se ha convertido en un hecho dentro de la actividad legislativa de algunas CC.AA (caso de las Comunidades de Castila La Mancha, Castilla León y Extremadura). Sin embargo, la nueva Ley no compensa, como afirma CASTILLO BLANCO, el déficit legislativo y la "poca atención" que tradicionalmente ha sufrido el PAS funcionario ${ }^{53}$. Tampoco ayuda - más bien complica- la entrada en vigor posterior del Estatuto Básico del Empleado Público (en adelante EBEP) en 2007, tramitado al mismo tiempo que la reforma de la propia LOU de 2001 operada en ese mismo año, generando de esta manera algunas dudas sobre la posibilidad de la

53 Castillo Blanco, Federico (2009) "El Estatuto Básico del Empelado Público y el régimen del personal al servicio de las Universidades públicas", en la obra "Comentario a la Ley Orgánica de Universidades". coord. por Julio V. González García. Ed. Civitas - Thomson Reuters. Madrid. Pág. 315. nota 10. 
derogación del Título X de la LOU, dedicado al PAS, dado su carácter no orgánico por parte del EBEP. La problemática ya se suscitó con anterioridad con el binomio LRU - Ley 30/1984 (vid. nota 9) pero, en opinión de GÓMARA HERNÁNDEZ, la situación debe calificarse como de "olvido del legislador para salvar el régimen ya consolidado del PAS de las universidades públicas ${ }^{54 ”, ~ e n t r a n d o ~ a ~ d e s c i f r a r ~ l a ~ i n t e r p r e t a c i o ́ n ~ d e l ~ a l-~}$ cance de una y otra norma al binomio ley general/ ley especial.

\section{1. "El personal funcionario de administración y servicios se regirá por la presente Ley y sus disposiciones de desa- rrollo..."}

El primer escalón de la legislación aplicable a los funcionarios del PAS, y por tanto de su Estatuto, idéntico tanto el art. 49 de la LRU como el a 73.3 de la LOU establecían, es la aplicación preferente de la propia Ley orgánica y sus disposiciones de desarrollo. La formula, lejos de despejar dudas, las promueve, ya que podría darse el hecho de que hubiera legislación de desarrollo, estatal y autonómica, que entrara a regular la función pública del PAS en las universidades. Por tanto, desde este ámbito legislativo sectorial - el de las Universidades- se podría dar lugar a un régimen estatutario de carácter básico - desde la acción legislativa estatal--, por un lado, y de desarrollo - desde la acción legislativa autonómica aunque también cabría la estatal-, por otro, para los funcionarios de las universidades públicas con lugar suficiente para la regulación estatutaria de las propias Universidades ${ }^{55}$.

Algunas CC. AA, en contraposición a la anterior LRU de 1983, han optado por legislar en materia de universidades dentro de su ámbito territorial con una idea de "totalidad" de tal manera que se incluyeran todas aquellas materias que la LOU otorga competencias directas y concretas a las CC. AA, junto a aquellas otras propiamente deducibles del servicio público de la educación superior. De ahí que la Le-

${ }^{54}$ Gómara Hernández, José Luis (2009) "El personal de administración y servicios de las Universidades públicas" en la obra Comentario a la Ley Orgánica de Universidades". coord. por Julio V. González García. Ed. Civitas - Thomson Reuters. Madrid. Pág. 574

${ }^{55}$ El Tribunal Supremo haciéndose eco de la doctrina constitucional sobre los Estatutos de las Universidades, reafirman su carácter autónomo: "Debe tenerse en cuenta, asimismo, que el Tribunal Constitucional, en Sentencias 55/1989 y 130/1991, ha declarado que los Estatutos de las Universidades, aunque tengan su norma habilitante en la Ley de Reforma Universitaria, no son en realidad normas dictadas en su desarrollo, sino reglamentos autónomos en los que se plasma la potestad de autoordenación de la Universidad en los términos que permite la ley, por lo que solamente puede tacharse de ilegal alguno de sus preceptos si contradice frontalmente las normas legales que configuran la autonomía universitaria, siendo válida toda norma estatutaria respecto de la cual quepa alguna interpretación legal." STS, contencioso sección 7, de 30 de junio de 1998 (ROJ: STS 8666/1998) No de Recurso: 6449/1995 |Ponente: GUSTAVO LESCURE MARTIN 
yes de universidades autonómicas hayan pasado a denominarse, con toda intención, como Ley de /del "universidades", "sistema de universidades", "ordenación del sistema de universidades... ${ }^{56}$. Todas ellas hacen referencia al PAS funcionario de las universidades públicas, con mayor o menor desarrollo, diseñando un régimen jurídico individualizado en cada comunidad Autónoma que, en algunos casos, llega incluso a alterar el sistema de fuentes de la propia LOU $^{57}$. Este es el caso, por ejemplo, del Texto Refundido de la Ley Andaluza de Universidades ${ }^{58}$ al establecer que el personal funcionario de administración y servicios se regirá por la Ley Orgánica de Universidades, por el Estatuto Básico del Empleado Público, por la legislación sobre función pública de la Junta de Andalucía, por dicha Ley y sus respectivas disposiciones de desarrollo, por los estatutos de las Universidades, así como por los acuerdos y pactos colectivos que le sean de aplicación, para el caso del PAS laboral. O el texto de Aragón, en el que se suprime toda referencia a la legislación de funcionarios estatal o autonómica: “el personal funcionario se regirá por la Ley Orgánica 6/2001, de 21 de diciembre, de Universidades, y por lo regulado en esta Ley así como por las disposiciones de desarrollo y por los Estatutos de la universidad. El personal laboral, además de las normas mencionadas, se regirá por la legislación laboral y por los convenios colectivos aplicables ${ }^{59}$ ". La cuestión a tener en cuenta es: en qué medida este desarrollo legislativo autonómico sectorial puede alterar el sistema de fuentes diseñado por el art. 73 de la LOU que establece, de forma clara, un ámbito material a la legislación "general" de funcionarios y, por tanto, legislación estatal. Desde luego que con ello, se alienta la confusión terminológica respecto del "grupo normativo" estatutario del PAS funcionario y se hace perder la verdadera función que la Ley orgánica pretende, que es la de generar un régimen estatutario propio compuesto por dos niveles normativos, en su caso, y un tercero que responde al ámbito de la autonomía universitaria. En efecto, la intención de la Ley es deslindar, desde su imbricación con la Ley orgánica estatal, que es su norma "cabecera", y sobre la base de la legislación sectorial de universidades un estatuto propio, al modo de otros funcionarios ligados

56 Estas leyes son: la Ley 6/2013, de 13 de junio, del Sistema universitario de Galicia, la Ley 3/2003, de 28 de marzo, de Universidades de Castilla y León, la Ley 3/2005, de 25 de abril, de Universidades de la Región de Murcia, el Decreto Legislativo 1/2013, de 8 de enero, por el que se aprueba el Texto Refundido de la Ley Andaluza de Universidades, la Ley 5/2005, de 14 de junio, de Ordenación del Sistema Universitario de Aragón, la Ley 3/2004, de 25 de febrero, del Sistema Universitario Vasco y la Ley $1 / 2003$, de 19 de febrero, de universidades de Cataluña.

57 Tanto la Ley 6/2013, de 13 de junio, del Sistema universitario de Galicia, en cambio, como la Ley 3/2003, de 28 de marzo, de Universidades de Castilla y León, nada dicen al respecto.

${ }^{58}$ Es el artículo 50 del Decreto Legislativo 1/2013, de 8 de enero, por el que se aprueba el Texto Refundido de la Ley Andaluza de Universidades

${ }^{59}$ Art. 38 de la Ley 5/2005, de 14 de junio, de Ordenación del Sistema Universitario de Aragón. 
a la prestación de un servicio público singular y determinado, y que el Tribunal Constitucional ha singularizado "entre aquellas situaciones jurídicas caracterizadoras del propio modelo de régimen estatutario de los funcionarios, que conforman la sustancia misma de ese régimen y sin las cuales no sería recognoscible ese estatuto ${ }^{60}$ ".

De ahí que se diseñara, de forma básica, en el original artículo 73 de la LOU, las funciones propias del PAS a quienes se les atribuyen los servicios la gestión técnica, económica y administrativa, así como el apoyo, asesoramiento y asistencia en el desarrollo de las funciones de la universidad, y que se desarrollarían más adelante al albur de la posterior reforma de la Ley en 2007. Esta reforma atribuye como funciones propias del personal de administración y servicios de las Universidades públicas, el apoyo, asistencia y asesoramiento a las autoridades académicas, el ejercicio de la gestión y administración, particularmente en las áreas de recursos humanos, organización administrativa, asuntos económicos, informática, archivos, bibliotecas, información, servicios generales, así como cualesquiera otros procesos de gestión administrativa y de soporte que se considere necesario para la Universidad en el cumplimiento de sus objetivos ${ }^{61}$. Esta disposición viene a deslindar de forma básica los "rolles" que han de desempeñar los dos grupos de funcionarios en la Administración universitaria, el PAS funcionario y el personal docente e investigador funcionario.

\section{a) Composición del PAS funcionario}

Precisamente la Ley orgánica define las características básicas de su régimen estatutario que pasa por atribuir directamente a las universidades las facultades de creación de escalas de "funcionarios propios ${ }^{62 ", ~ d e ~ a c u e r d o ~ c o n ~ l o s ~ g r u p o s ~ d e ~ t i t u l a c i o ́ n ~}$ exigidos de conformidad con la legislación general de la función pública ${ }^{63}$. Disposición en la que se basan los Estatutos universitarios para la creación, y, por tanto, también a su modificación y supresión, de las Escalas de sus funcionarios tanto en su número, como en tipos y especialidades, algo que tan sólo está reservado a una ley ${ }^{64}$. La

${ }^{60}$ STC 140/1990, de 20 de septiembre. Conflicto positivo de competencia núm. 192/85

${ }^{61}$ Se trata del número 2 del artículo 73, añadido por el apartado setenta y seis del artículo único de la Ley Orgánica 4/2007, de 12 de abril, por la que se modifica la Ley Orgáncia 6/2001, de 21 de diciembre, de Universidades

${ }^{62}$ El término empleado por al Ley en el art. 75.1 no es muy afortunado al señalar "escalas de personal propio".

${ }^{63} \mathrm{El}$ texto finalmente no incorporó una enmienda del grupo socialista que hubiera sido clarificadora en relación con el sistema de fuentes: "de conformidad con la legislación básica de funcionarios y la correspondiente de la Comunidad Autónoma"

${ }^{64}$ En efecto así lo establece el art. 75.2 de la Ley 7/2007, de 12 de abril, del Estatuto Básico del Empleado Público, que a su vez recoge los pronunciamientos al respecto del Tribunal Constitucional. 
cuestión que se suscita aquí es si hay una predeterminación legislativa suficiente ${ }^{65}$ para que los Estatutos de las Universidades - normas reglamentarias, aunque reglamentos autónomos- puedan contener dicha regulación o bien hubiera sido necesaria una intervención legislativa sobre esta cuestión. El Tribunal Constitucional señala que "medidas de esta intensidad, unificación y extinción, sobre Cuerpos y Escalas requieren, para su posible adopción por el Gobierno, de una predeterminación legislativa suficiente por medio de la cual se evite que resida en el Gobierno mismo, sin límites o con límites imprecisos, una potestad incondicionada para alterar la estructura en Cuerpos y Escalas de la Administración Pública66". Téngase en cuenta que, como hemos expuesto más arriba, la Ley 30/1984 de 2 de agosto, intervino unificando las diversas escalas de las Universidades públicas. No creemos que la LOU sea "predeterminación legislativa suficiente" para que los Estatutos universitarios puedan crear, modificar o suprimir Escalas propias de funcionarios. En primer término, porque la legislación básica de funcionarios así lo establece de forma clara y manifiesta ${ }^{67}$. En segundo término, porque las facultades dimanantes de la autonomía universitaria se refieren directamente a las facultades de selección, formación y promoción pero no en cuanto a su estructuración y el contenido de la relación estatuaria, la cual "hace referencia a aquellas situaciones juridicas caracterizadoras del propio modelo de régimen estatutario de los funcionarios, que conforman la sustancia misma de ese régimen y sin las cuales no sería recognoscible ese estatuto ${ }^{68}$, , exigiéndose para ello de regulación legal. Tampoco la facultad de regular sus propias normas de organización y funcionamiento, como contenido propio de la autonomía universitaria, son elementos determinantes para considerarlas como normas habilitantes para la creación de Escalas de funcionarios. En tercer lugar, la doctrina del Tribunal Constitucional es clara, al respecto, al señalar que "las normas que disciplinen estos ámbitos - la creación e integración, en su caso, de cuerpos y escalas funcionariales]- serán, en el concepto constitucional, ordenadoras del estatuto de los funcionarios públicos, pues todas ellas interesaran directamente a las relaciones entre estos y las administraciones a las que sirven, configurando asi el régimen jurídico en el que pueda nacer y desenvolverse la condición de funcionario y ordenando su posición propia en el seno de la administración ${ }^{69 " . ~ E n ~ c u a r t o ~ t e ́ r m i n o, ~ l a ~ L O U ~ n o ~}$ parece cerrar el sistema normativo en esta materia concreta ya que cabría la colabo-

65 STC 99/1987, de 11 de junio, recurso de inconstitucionalidad núm. 763/84. FJ $3^{\circ}$.

66 STC 99/1987, de 11 de junio, recurso de inconstitucionalidad núm. 763/84. FJ $3^{\circ}$

67 "Los cuerpos y escalas de funcionarios se crean, modifican y suprimen por Ley de las Cortes Generales o de las Asambleas Legislativas de las Comunidades Autónomas".. Es más "Cuando en esta Ley se hace referencia a cuerpos y escalas se entenderá comprendida igualmente cualquier otra agrupación de funcionarios" Art. 75.2 y 3 del EBEP.

${ }^{6}$ STC 140/1990, de 20 de septiembre. Conflicto positivo de competencia núm. 192/85.

69 STC 99/1987, de 11 de junio, recurso de inconstitucionalidad núm. 763/84. 
ración legislativa y reglamentaria de ella misma pero como disposiciones de desarrollo de la misma. De esta manera, no creemos que los Estatutos universitarios pudieran estar incluidos dentro de este grupo normativo dado su carácter de reglamentos autónomos cuyo límite vendría dado precisamente por el carácter legislativo que se otorga a la creación, integración o desaparición de las escalas de funcionarios. Es además significativo que la Ley no se remita a los Estatutos para regular la creación de escalas de personal propio, cuando sí lo hace en otros aspectos del estatuto de PAS funcionario, razón por la que fuera previsible desde la visión del legislador "universitario" una intervención legislativa al respecto, bien desde la LOU como norma cabecera, bien desde la legislación general de función pública.

De igual forma, la Ley orgánica también establece que la prestación de los servicios atribuidos al PAS, lo sean además de los funcionarios propios, por el personal funcionario perteneciente a los cuerpos y escalas de otras Administraciones públicas (incluyendo dentro de esta concepto también a otras universidades públicas), lo cual significa que los instrumentos de ordenación del personal, las relaciones de puestos de trabajo, deben contemplar esta posibilidad, de tal manera que dichos puestos de trabajo no queden limitados al personal funcionario de las Escalas de cada universi$\mathrm{dad}^{70}$. De igual forma, ex lege, corresponde a las Universidades determinar su régimen retributivo, con la limitación cuantitativa máxima que determine la Comunidad Autónoma, que es la Administración a la que están vinculadas ${ }^{71}$, régimen que se ha de plasmar en los presupuestos de las mismas universidades para los que gozan de autonomía económica y financiera, si bien el propio contenido del mismo, debe situarse en el marco de las bases que dicte el Estado ${ }^{72}$, a quien compete la promulgación de una disposición normativa específica estatal sobre esta materia. De ahí que el régimen retributivo del PAS funcionario corresponda de forma prioritaria al Estado en primer término y las Universidades, en segundo lugar, con la salvedad de sus límites cuantitativos máximos, y de conjunto, que corresponde a las CG.AA. Sin embargo, la reforma de 2007 de la LOU, introdujo, dentro de esta cuestión retributiva y de forma indirecta, a las CG.AA al señalar que, en concurrencia con el Gobierno, las Comunidades Autónomas podrían establecer programas de incentivos ligados a méritos

${ }^{70}$ Art. 73.1 de la LOU.

71 Normalmente las Administraciones autonómicas hacen referencia a este aspecto en las leyes anuales de presupuestos por partida doble, en primer término al incluirlas dentro de su sector público y,en segundo lugar, por dedicar un apartado específico al régimen retributivo general a las universidades públicas (vid. por ejemplo los art. 21.1 c) y el art. 32 de la Ley 3/2014, de 22 de diciembre, de Presupuestos Generales de la Comunidad de Madrid para el año 2015).

72 Art. 74.2 de la LOU 
individuales para el PAS, vinculados a su contribución en la mejora de la investigación y la transferencia de conocimiento ${ }^{73}$. Esta reforma no altera sustancialmente el régimen retributivo general del PAS funcionario de la Universidades públicas que corresponde de forma sustancial al Gobierno central por lo que el Real Decreto $1545 / 1987$, de 11 de diciembre, por el que se establecía el régimen de retribuciones de los funcionarios de Administración y Servicios de las Universidades de competencia de la Administración del Estado, siga en vigor, a pesar de las adaptaciones a la realidad en algunas de sus cláusulas. Al señalar que las facultades de selección del PAS funcionario corresponden a las Universidades, la Ley explicita una facultad directamente incardinada en la autonomía universitaria ${ }^{74}$, de ahí que estas materias constituyan uno de los núcleos esenciales del estatuto específico del PAS funcionario y se anteponga a cualquier sistema de fuentes diseñado por la ley. El modo y el quantum corresponde a la Universidad que debe observar, no obstante, lo que establezcan las leyes y los Estatutos que le sean de aplicación, atendiendo a los principios de igualdad, mérito y capacidad. De ahí el tenor literal de este último inciso del art.75.2, que constituye a los Estatutos como la fuente de segundo orden respecto a la Ley (las leyes y los Estatutos dice textualmente), tampoco sea muy significativo ya que bajo el término "las leyes" nuevamente nos remite al sistema de fuentes, a su vez diseñado por el art. 73.3 que viene a ser como el sistema general de fuentes aplicativo para el Estatuto del PAS funcionario. Por tanto, dentro del término "las leyes" hemos de entender incluidas la propia Ley orgánica, y sus disposiciones de desarrollo, junto a la legislación general de funcionarios.

\section{b) Movilidad y carrera administrativa del PAS funcionario}

La Ley Orgánica se preocupa en diseñar la provisión de puestos del PAS funcionario de las universidades - aunque con cierta imprecisión técnica- que se realizará, según dice, por el sistema de concursos, a los que podrán concurrir tanto el personal propio de aquéllas como el personal de otras universidades. Es ciertamente un aspecto en "la determinación de las condiciones en que han de desarrollar sus actividades", inciso este que es incardinado dentro de las atribuciones propias de la autonomía universitaria. El personal perteneciente a cuerpos y escalas de las Administraciones pú-

${ }^{73}$ El contenido se corresponde con el número 3 del artículo 74, introducido por el apartado setenta y siete del artículo único de la Ley Orgánica 4/2007, de 12 de abril, por la que se modifica la Ley Orgánica 6/2001, de 21 de diciembre, de Universidades

${ }^{74}$ El art. 2.2 e) de la Ley Orgánica 6/2001, de 21 de diciembre de Universidades, señala que uno de los contenido de la autonomía universitaria es "La selección, formación y promoción del personal docente e investigador y de administración y servicios, así como la determinación de las condiciones en que han de desarrollar sus actividades". Lo cual supone un reforzamiento con el carácter orgánica de este precepto. 
blicas pueden concurrir en las condiciones que reglamentariamente se determinen. Regulación que se completa con el establecimiento de que sólo podrán cubrirse por el sistema de libre designación ${ }^{75}$ aquellos puestos que se determinen por las universidades atendiendo a la naturaleza de sus funciones, y de conformidad con la normativa general de la función pública. Para este caso se antepondrían las normas que al respecto puedan dictarse al respecto desde las propias universidades con el único condicionante, entendemos, de la legislación básica.

Sobre la movilidad del PAS funcionario, el art. 76 bis de la LOU, añadido por la reforma de 2007, realiza un mandato a las universidades sumamente interesante, y es que debían promover las condiciones para que el personal de administración y servicios pueda desempeñar sus funciones en universidades distintas de la de origen. Lo cual viene a incidir en diseños de políticas de movilidad y de carrera interadministrativa para el PAS funcionario de otras universidades públicas a los que se considera naturalmente como los destinatarios ideales para el desempeño del puesto de trabajo por la similitud de funciones. Quizás no estuviera muy lejano en la mente del legislador, el reflejo hacia el PAS funcionario, del carácter de «comunicables» entre las diferentes Universidades, (carácter interuniversitario) que reflejara en su día el Tribunal constitucional para los Cuerpos docentes ${ }^{76}$. Sea como fuere, los estatutos de las universidades son los facultados por la Ley para establecer las normas que diseñen la provisión de puestos que pueden contemplar también los convenios entre las Universidades o con otras Administraciones públicas que garanticen el derecho a la movilidad de su respectivo personal bajo el principio de reciprocidad ${ }^{77}$. Es más, la Ley considera indispensable la movilidad interadministrativa /interuniversitaria del PAS funcionario, en sus realidades diversas ${ }^{78}$. Lo cual, significa que los instrumentos

75 Téngase en cuenta que "En el procedimiento de libre designación rigen también los principios de mérito y capacidad, pero, a diferencia del concurso, en que están tasados o predeterminados los que ha decidir el nombramiento, la Administración tiene reconocida una amplia libertad para decidir, a la vista de las singulares circunstancias existentes en el puesto de cuya provisión se trate, cuáles son los hechos y condiciones que, desde la perspectiva de los intereses generales, resultan más idóneos o convenientes para el mejor desempeño del puesto". STS, contencioso sección 7, de 3 de diciembre de 2012 (ROJ: STS 8373/2012) No de Recurso: 339/2012 |Ponente: VICENTE CONDE MARTIN DE HIJAS

${ }^{76}$ STG 26/1987, de 27 de febrero. Recurso de inconstitucionalidad núm. 794/83, FJ 3․ En este mismo sentido la STC 146/1989, de 21 de septiembre, Conflicto positivo de competencia núm. 195/85.

${ }^{77}$ Esta posibilidad, mejor mandato, se introdujo en la reforma de la Ley en 2007, redactado por el apartado setenta y ocho del artículo único de la Ley Orgánica 4/2007, de 12 de abril, por la que se modifica la Ley Orgánica 6/2001, de 21 de diciembre, de Universidades

${ }^{78}$ Los Estatutos de la Universidad Complutense de Madrid van más allá al incluir a la Unión Europea, en la movilidad voluntaria de su respectivo personal, bajo el principio de reciprocidad (art. 123). 
básicos de ordenación del personal y de organización administrativa, las relaciones de puestos de trabajo ${ }^{79}$, han de concretar dicho mandato. En efecto, son éstas las que deben reflejar la diversidad de funcionarios que puedan prestar servicio dentro de cada administración universitaria. No ha de olvidarse que, precisamente, son las que deben establecer los requisitos de desempeño de los puestos de trabajo, por lo que, de sus cláusulas, penden la realidad o no de la movilidad interuniversitaria de los distintos funcionarios del PAS. De ahí que algunos Estatutos universitarios hayan establecido, la relación de puestos de trabajo (RPT), como disposición ${ }^{80}$ que debe incluir necesariamente la forma de provisión, la denominación y características del puesto de trabajo, funciones, grado de responsabilidad y dedicación, turno, retribuciones básicas y complementarias correspondientes, así como la indicación de su desempeño por personal funcionario o laboral, atendiendo a la naturaleza del mismo ${ }^{81}$. Incluso se realizan previsiones de su revisión, en algunos casos, con carácter anual, y la posibilidad de negociación con los órganos de representación del personal ${ }^{82}$. Este hecho hoy en día goza del reconocimiento legislativo a través del art. 37 del EBEP y de

${ }^{79}$ A este respecto téngase en cuenta nuestro artículo sobre la incidencia real que tienen las RPTs en la movilidad de los funcionarios: "Elementos necesarios o estructurales de las relaciones de puestos de trabajo del personal funcionario en el Estado y los municipios desde las normas y la jurisprudencia" Revista Vasca de Administración Pública. Rev. N 99/100 de 2014; y el artículo "Régimen jurídico básico de las relaciones de puestos de trabajo y estatuto de los funcionarios locales” Revista de Estudios de Administración Local y Autonómica. INAP, n 3. Enero-junio 2015

${ }^{80}$ La STS, contencioso sección 7, de 5 de febrero de 2014 (ROJ: STS 902/2014) No de Recurso: 2986/2012 |Ponente: VICENTE CONDE MARTÍN DE HIJAS, ha supuesto un cambio significativo en la doctrina casacional respecto a las RPT, las cuales han sido calificadas a todos los efectos como actos administrativos condición.

${ }^{81}$ Es el caso por ejemplo del art. 115.3 de los Estatutos de la Universidad de Sevilla, aprobados por Decreto 324/2003, de 25 de noviembre.; o el art. 93del Decreto 214/2003, de 16 de octubre, del Consejo de Gobierno, por el que se aprueban los Estatutos de la Universidad Autónoma de Madrid; o el art. 154 del Decreto 237/2003, de 8 de octubre, por el que se aprueban los Estatutos de la Universidad Autónoma de Barcelona; o el art. 41.2 del Decreto 14/2014, de 30 de enero, por el que se aprueban los estatutos de la Universidad de Santiago de Compostela

82 "hemos de tener presente que, sobre la cuestión de fondo planteada por la Comunidad Autónoma de La Rioja, la jurisprudencia sostiene que, ciertamente, las relaciones de puestos de trabajo deben ser objeto de negociación colectiva" STS, contencioso sección 7, del 8 de noviembre de 2013 (ROJ: STS 5599/2013) No de Recurso: 3105/2012 | Ponente: PABLO MARÍA LUCAS MURILLO DE LA GUEVA. Sentencia que a su vez se hace eco de una frondosísima jurisprudencia al respecto: "la sentencia de 21 de junio de 2013 (casación 926/2012) dice al respecto: "Esta Sala se ha pronunciado de forma reiterada sobre la cuestión planteada en el actual recurso de casación poniendo de manifiesto la necesidad de posibilitar una auténtica negociación sobre las Relaciones de Puestos de Trabajo de los funcionarios públicos. Entre las más recientes las sentencias de 26 de septiembre de 2011 (rec. num. 1546/2008); 6 de julio de 2011 (rec. num. 2580/2009); 21 de junio de 2011 (rec. num. 4175/2009); 18 de marzo de 2011 (rec. num. 
una línea jurisprudencial muy amplia, tal y como hemos señalado en la nota anterior, si bien con el límite de las potestades de organización que este mismo artículo señala ${ }^{83}$. Es más, las RPT son una manifestación especial de la autonomía universitaria $^{84}$. Por tanto, los sistemas de provisión de puestos de trabajo en las Administraciones universitarias están directamente ligadas al estatuto específico del PAS funcionario porque son una manifestación de su autonomía, y el sistema de fuentes pasa por contemplar en primer término su especificidad, de tal manera que desde la LOU se realiza un remisión directa a los Estatutos de las Universidades como primera fuente ordenadora que, no obstante, deben contemplar la normativa básica general de los funcionarios públicos. Otro tanto podemos decir respecto del perfeccionamiento y promoción profesional del PAS funcionario, también contemplado en el art. 2.2 e) de la LOU, y, por tanto, directamente vinculados con la autonomía universitaria. Todo lo cual supone que las Universidades han de ocuparse, con preferencia a cualquier otra Administración, de los sistemas de carrera administrativa, la formación continua y evaluación de dichos funcionarios. En efecto, la reforma de 2007, de la LOU, incluyó un nuevo artículo ${ }^{85}$ con estas disposiciones, de tal manera que la formación permanente del personal de administración y servicios, y el fomento de programas que aumenten sus habilidades y competencias profesionales son una obligación para las Universidades. Aquí debe advertirse que la Ley no ha hecho sino

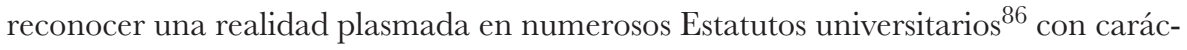
ter previo y que, incluso en algunos casos, han ido más allá al contemplar, por ejem-

6325/2008); 7 de noviembre de 2011 (rec. num. 4637/2010); 2 de diciembre de 2010 (rec. num. 4775/2009); y 19 de julio de 2010 (rec. num. 3157/2009)". Trecoge de la anterior sentencia de 26 de septiembre de 2011 (casación $1546 / 2008) "$

83 "Este precepto permite deducir que, en lo que hace a las decisiones sobre el ejercicio de la potestad de organización, se establece para ellas como norma inicial la exclusión de la obligatoriedad de la negociación; y una salvedad a tal norma, que está referida a las decisiones organizativas que repercutan en las condiciones de trabajo que conforme a lo dispuesto en el apartado 1 del propio artículo son negociables, y significa que deberán negociarse exclusivamente estas condiciones. Siendo la consecuencia que se deriva de lo anterior que no basta para que opere la mencionada salvedad que la disposición organizativa afecte a los puestos de trabajo, pues debe subrayarse que la estructura que se da a la Consejería es un acto condición de otros sucesivos que deberán adaptarse necesariamente al Reglamento organizativo". STS, contencioso sección 7 de 29 de mayo de 2015 (ROJ: STS 2399/2015) No de Recurso: 648/2014 |Ponente: JOSÉ DÍAZ DELGADO.

${ }^{84}$ Art. 2.2. i) de la LOU

${ }^{85}$ Artículo 76 bis introducido por el apartado setenta y ocho del artículo único de la Ley Orgánica 4/2007, de 12 de abril, por la que se modifica la Ley Orgánica. 6/2001, de 21 de diciembre, de Universidades

86 Así por ejemplo el art. 137 de los Estatutos de la Universidad Complutense de Madrid, aprobados mediante Decreto 58/2003, de 8 de mayo, o 
plo, que los conocimientos adquiridos sean valorados a los efectos del acceso a puestos, categorías o escalas de nivel superior ${ }^{87}$.

\section{c) Participación institucional del PAS funcionario}

Señalaba el Tribunal Constitucional que la autonomía universitaria "se proyecta internamente, y ello aun con ciertos límites, en la autoorganización de los medios de que dispongan las Universidades para cumpliry desarrollar las funciones que, al servicio de la sociedad, les han sido asignadas $^{88} "$, de ahí que la LOU asegure la participación del personal de administración y servicios en los órganos de gobierno y representación de las Universidades, para la cual se establece, de manera exclusiva, como sistema de fuentes la propia Ley orgánica y los Estatutos. Quizás el artículo responda a la monopolización que el apartado 4 del art. 2 de la Ley hace de la autonomía universitaria en su proyección sobre dos sectores de la Comunidad universitaria, los docentes e investigadores y los estudiantes, al señalar la doctrina del Tribunal Constitucional que la autonomía universitaria "encuentra su razón de ser en la protección de la libertad académica, en su manifestación de libertad de enseñanza, estudio e investigación, frente a todo tipo de injerencias externas, de manera que, en todo caso, la libertad de ciencia quede garantizada, tanto en su vertiente individual como institucional, entendida ésta, además, como la correspondiente a cada Universidad en particular ${ }^{89 ",}$ $\mathrm{y}$, en especial, al último inciso del mismo, en el que se hace alusión a que las Universidades han de rendir cuentas del uso de sus medios y recursos a la sociedad. Téngase en cuenta que corresponde al PAS funcionario la gestión técnica, económica y administrativa, así como el apoyo, asesoramiento y asistencia en el desarrollo de las funciones de la universidad, el soporte a la investigación y la transferencia de tecnología y a cualesquiera otros procesos de gestión administrativa necesarios para que la universidad en el cumplimiento de sus objetivos ${ }^{90}$. Funciones que se proyectan " $a d$ intra" mediante la asistencia y apoyo directo a los restantes estamentos universitarios y "ad extra" en cuanto que son los encargados de efectivamente autenticar ante la sociedad que los medios económicos y materiales puestos a disposición de la universi-

${ }^{87}$ Art. 119 del Decreto 324/2003, de 25 de noviembre, por el que se aprueba el Estatuto de la Universidad de Sevilla.

88 STC 106/1990, de 6 de junio. Cuestiones de inconstitucionalidad acumuladas núms. 1976, $2176,2442,2491,2492,2535$ y 2593/89 y 251 y $439 / 90$.

${ }^{89}$ STC 223/2012, de 29 de noviembre. Recurso de inconstitucionalidad núm. 1671/2002. La cual hace un resumen de la doctrina reflejadas en otras sentencias: STC 106/1990, de 6 de junio, FJ 6, que resume la jurisprudencia anterior: SSTG 26/1987, de 27 de febrero, FJ 4; y 55/1989, de 14 de marzo, FJ 2.

${ }^{90}$ Art. 73.2 de la LOU. 
dad cumplen con las funciones que la sociedad exige de las Universidades y que cabalmente se señalan en el apartado segundo del art. $1^{\circ}$ de la LOU $^{91}$. De ahí que sea especialmente importante su participación en los órganos institucionales de la Universidad porque la autonomía universitaria se predica también en su vertiente colectiva o institucional ${ }^{92}$ en cuanto que la comunidad universitaria es una realidad multiforme compuesta de tres estamentos: personal docente e investigador, el alumnado y el personal de administración y servicios.

En líneas generales, los Estatutos y otras disposiciones de desarrollo de las Universidades públicas han asumido el plan normativo que la Ley pretendía. Así, por ejemplo, y entre otros muchos, los Estatutos de la Universidad Autónoma de Madrid proclaman como derecho del PAS la participación en los órganos de gobierno, de representación y de administración ${ }^{93}$. Derecho que se traduce en un porcentaje correspondiente de presencia en los distintos órganos de gobierno: Consejo Social, Claustro, Consejo de Gobierno, Juntas de Facultad, Consejos de Departamento al modo y semejanza a los otros dos sectores. Esta peculiaridad propia de la Universidad -su carácter netamente corporativo- hace que el sistema de fuentes, respecto de esta participación, se cierre en este grupo normativo de origen exclusivo en la legislación sectorial universitaria y desde la propia capacidad normativa de la institución, de tal manera que sólo cabría el régimen de supletoriedad establecido por la propia normativa de las Universidades públicas ${ }^{94}$. Es más, "los Estatutos de cada Universidad,

91 "Las exigencias del servicio público (es un) como límite a las facultades que conforman el núcleo esencial de la autonomía universitaria se desprende de la concreta dicción de la citada STC 156/1994 (...) porque la condición de servicio público de la enseñanza universitaria justifica ciertas restricciones legales en los ámbitos que conforman el núcleo esencial de la autonomía universitaria" STC 87/2014, de 29 de mayo, Cuestión de inconstitucionalidad núm. $2854 / 2013$.

92 STC 26/1987, de 27 de febrero de 1987. Recurso de inconstitucionalidad núm. 794/83.

93 Art. 98 c) del Decreto 214/2003, de 16 de octubre, del Consejo de Gobierno, por el que se aprueban los Estatutos de la Universidad Autónoma de Madrid. También en el art. 163.2 a) del Decreto 246/2003, de 8 de octubre, por el que se aprueba el Estatuto de la Universidad de Barcelona, o el art. 109 b) del Decreto 324/2003, de 25 de noviembre, por el que se aprueba el Estatuto de la Universidad de Sevilla, o también el art. 180.1 e) del Decreto 128/2004, de 30 de julio, por el que se aprueban los Estatutos de la Universidad de Valencia (Estudio General)...entre otros muchos.

${ }^{9}$ Así, por ejemplo, la Disposición Adicional $2^{\mathrm{a}}$ del Reglamento Electoral de la Universidad de Salamanca (Aprobado en la sesión del Claustro Universitario celebrada el día 14 de mayo de 2013) "Se entenderán como normativas supletorias a este Reglamento, la Ley Orgánica de Régimen Electoral Genera y la Ley de Régimen Jurídico de las Administraciones Públicas y del Procedimiento Administrativo Común". También, en este mismo sentido la Disposición adicional $3^{\mathrm{a}}$ del Reglamento Electoral de la Universidad Politécnica de Madrid, aprobado por el Claustro Universitario de en su Sesión del 11 de diciem- 
ante la falta de una regulación expresa en la normativa estatal, son los que deben establecer el procedimiento electoral respetando el marco legal ${ }^{95}$ ".

El PAS funcionario, pues, forma parte de la comunidad universitaria de tal manera que ayuda a delimitar sus intereses, como expresión de su propia autonomía, por la participación en dichos órganos de gobierno. De ahí que, como se afirmaba en el ATG 19/2012, de 30 de enero de 2012, la Comunidad universitaria sea considerada como un "cuerpo vivo".

\section{2. “...Se regirá además por la legislación general de funcio- narios, que le sea de aplicación y, en su caso por las dis- posiciones de desarrollo de ésta que elaboren las Comu- nidades Autónomas..."}

La única diferencia - aunque sustancial- con el tenor literal del art. 49.3 de la LRU de 1983 es que aquélla establecía, la aplicación al PAS funcionario, de "la legislación de funcionarios que le sea de aplicación". Lo cual venía a significar que, en contraposición con el siguiente escalón del sistema de fuentes, el de las CC.AA, le era aplicable toda la legislación de función pública de la AGE, básica o no, con las únicas salvedades comentadas en el punto anterior. De ahí que un conjunto notable de normas legales y reglamentarias del régimen estatutario de los funcionarios de la AGE, les fuese de aplicación directa, no supletoria, (vid. punto 3 "ut supra") y que, como ya expresamos, fuese objeto de inclusión el PAS funcionario en las mismas de manera expresa o tácita - las más de las veces- ${ }^{-}$. Naturalmente que esta circunstancia hacía más que suficiente que el PAS funcionario pudiera estar adscrito dentro del ámbito de aplicación de la Ley 30/1984, de 2 agosto, ya que su estatuto específico venía a estar constituido por la LRU, y sus disposiciones estatales de desarrollo, la Ley 30/1984, de 2 de agosto y sus disposiciones de desarrollo. Todo un grupo normativo de procedencia genuinamente estatal generador de un estatuto específico, a pesar haberse materializado el proceso de transferencias de las Universidades, en un primer período 1985-1986 y, en un segundo, 1995-1996, cuyos procesos se demostraron con una influencia material y administrativa, sobre el PAS funcionario, de facto, escasa. La cuestión a dilucidar es: hasta dónde podría entrar la legislación autonómica de desarrollo sobre funcionarios, formalmente no transferidos, y a los que les es

bre de 2014 y el art. 2 del Reglamento Electoral General de la Universidad de Granada aprobado por el Consejo de Gobierno en sesión de 20 de febrero de 2012.

95 STS, contencioso sección 7, de 30 de junio de 1998 (ROJ: STS 8666/1998) N Ne Recurso: 6449/1995 |Ponente: GUSTAVO LESCURE MARTIN 
de aplicación la legislación estatal antedicha. Ya vimos cómo la legislación autonómica sobre función pública apenas incluyó dentro de su ámbito de aplicación, por lo que el "tramo" autonómico del estatuto del PAS funcionario no se demostró muy significativo. El PAS funcionario, pues, seguía teniendo un sistema normativo ampliamente incardinado en la función pública estatal.

La cuestión, entendemos, sufre una ligera transformación con la LOU de 2001. En efecto, en primer término, el art. 73 de la reforma presentada, fue enmendado en el Congreso ${ }^{96}$, sin éxito, pretendiéndose que la redacción del art. 49.3 de la LRU permaneciera en el texto, pero finalmente se mantuvo la redacción del proyecto de Ley que, finalmente, quedaría en su redacción definitiva actual. De esta manera, el siguiente escalón normativo estaría constituido por la "legislación general de funcionarios, que le sea de aplicación". El término "legislación general" parece hacer referencia a la legislación básica de función pública aunque tampoco podemos establecer una relación mimética con ésta ${ }^{97}$, si bien con el límite de la "que le sea de aplicación". Si tenemos en cuenta lo establecido por el art. 2 del Estatuto Básico del Empleado Público (desde ahora EBEP) que dispone su completa aplicación al PAS funcionario de las Universidades $^{98}$, hemos de entender que esta aplicación se ve limitada por las limitaciones impuestas precisamente por la propia LOU, la legislación universitaria de desarrollo de ésta y por los propios Estatutos de las Universidades, según explicaremos. De esta manera, el EBEP debió matizar su aplicabilidad al PAS funcionario de las Universidades en la medida en que su legislación peculiar-enmarcada dentro de una Ley Orgánica- no dispusiera otra cosa. Hubiera sido, pues, mucho más correcto para el PAS funcionario un texto cercano al que se prevé en el punto $3^{\circ}$ de dicho artículo del EBEP $^{99}$ y que se manejó en algún proyecto de Ley del EBEP anterior al

\footnotetext{
${ }^{96}$ Fue la enmienda n 573 presentada por el Grupo Parlamentario Catalán (Convergència i Unió).

${ }^{97}$ La STC 141/2013, de 11 de julio, Recurso inconstitucionalidad núm. 1735/2002, señalaba que "Nada impide entender que una eventual regulación Navarra sobre el régimen estatutario del personal de administración y servicios será una "Disposición de desarrollo" de la "legislación general de funcionarios" en el sentido del art. 73.3, de aplicación preferente en Navarra siempre que respete los derechos y obligaciones esenciales de los funcionarios públicos establecidos por la legislación básica del Estado. A la luz del art. 73.3 LOU deben entenderse igualmente las referencias más sintéticas que se contienen en los arts. 75.1 y 76.1 LOU a la "legislación general" o a la "normativa general" de la función pública". La cuestión viene dada porque la Comunidad Foral de Navarra entendía que el artículo 73.3 LOU alteraba sus competencias sobre función pública y que debían ser interpretada la cláusula "legislación general de funcionarios" sobre sus propias disposiciones de función pública basándose en el régimen peculiar de su Estatuto de autonomía respecto de esta materia que otorga un carácter y alcance reforzado respecto a otras Comunidades Autónomas (art. 49 LORAFNA).

${ }^{98}$ Art. 2.1 de la Ley 7/2007, de 12 de abril, del Estatuto Básico del Empleado Público

${ }^{99}$ La redacción de dicho apartado es "El personal docente y el personal estatutario de los Servicios de Salud se regirán por la legislación especifica dictada por el Estado y por las Comunidades Autónomas en el ámbito de sus respecti-
} 
finalmente presentado ${ }^{100}$. E, incluso, la fórmula expresada por el EBEP en relación con las policías locales ofrece similitudes innegables, en su sistema de fuentes, con el PAS funcionario de las universidades públicas ${ }^{101}$.

Por su parte la legislación básica estatal puede verse completada "en su caso por las disposiciones de desarrollo de ésta que elaboren las Comunidades Autónomas". Remisión que no altera el tenor literal del art. 49. 3 de la LRU. Este escalón estaría llamado a realizar el denominado, por CASTILLO BLANCO, como el proceso de "interiorización autonómica del personal de administración y servicios ${ }^{102}$ ". A pesar de esta posibilidad, el resultado de regulación estatutaria del PAS funcionario por parte de la legislación autonómica de función pública, según hemos podido comprobar más arriba, ha sido más bien escaso aunque con mayor incidencia desde la promulgación de la LOU en 2001.

Pero es que la propia ley sigue matizando las facultades legislativas de las CCAA como si realmente no fuera esencial para configurar el estatuto del PAS funcionario de las Universidades públicas. En efecto, el término "en su caso" parece advertir que la acción normativa autonómica sobre el PAS funcionario estaría limitada, en primer lugar, por la legislación sectorial universitaria que se hubiere dictado, la cual tan sólo estaría limitada por la legislación básica de función pública estatal, y los propios Estatutos universitarios como referentes del ejercicio de la autonomía universitaria. De esta manera, la legislación autonómica sólo sería aplicable, en realidad, en última instancia de las anteriores, ya que en muchos de los apartados del régimen de derechos y deberes funcionariales, tal y como hemos señalado más arriba, se anteponen los Estatutos universitarios a la legislación autonómica de función pública.

Pero aún hay más ¿podríamos señalar que dentro de la expresión "en su caso" se incluiría propiamente la legislación de funcionarios dictada por la AGE en desa-

\footnotetext{
vas competencias y por lo previsto en el presente Estatuto, excepto el Capitulo II del Título III, salvo el artículo 20, y los artículos 22.3, 24 y 84"

${ }^{100}$ En el proyecto se incluía" al PAS, junto al PDI como objeto de legislación específica dentro texto articulado para luego enviarlo a una disposición adicional 6a , en la que se decía: "El personal de Administración y Servicios de las Universidades se regirá por la presente Ley, por las normas de desarrollo dictadas por las correspondientes Administraciones Públicas y por los Estatutos de su Universidad"

${ }^{101}$ En efecto el art. 3.2 establece: "Los Cuerpos de Policía Local se rigen también por este Estatuto y por la legislación de las Comunidades Autónomas, excepto en lo establecido para ellos en la Ley Orgánica 2/1986, de 13 de marzo, de Fuerzas y Cuerpos de Seguridad"

102 CASTILLO Blanco, Federico “op. cit.” Pág. 347.
} 
rrollo del EBEP como un plus a las anteriores limitaciones? Creemos que sí. En primer término porque, por ejemplo, para el caso de provisión de puestos de trabajo mediante libre designación, se acude en la LOU a expresiones tales como "la normativa general de la función pública" a la hora de determinar el sistema de aplicación particular, o para el caso del personal perteneciente a cuerpos y escalas de otras Administraciones públicas, para prestar servicio en la Universidades públicas, podrá concurrir en las condiciones que "reglamentariamente se determinen". Cuál sea esa reglamentación es evidente que podría ser determinada por la propia AGE dado que puede afectar a cuerpos y escalas propias o de las Administraciones locales, incluso puede hacer referencia a Reglamentos de desarrollo de los propios Estatutos universitarios $^{103}$. La cuestión fundamental es que el PAS funcionario no es propiamente personal funcionario de las CGAA, como tampoco lo es el Personal docente e investigador funcionario de las Universidades públicas ${ }^{104}$ para el que curiosamente la LOU establece un sistema normativo en el que las CCAA tienen ciertas facultades normativas, en este caso incluso anteriores a la propia legislación básica estatal. En efecto, en su art. 56.2, cuya redacción se reformó en 2007, se dice expresamente que "El profesorado funcionario se regirá por las bases establecidas en esta Ley y en su desarrollo, por las disposiciones que, en virtud de sus competencias, dicten las Comunidades Autónomas, por la legislación general de funcionarios que les sea de aplicación y por los estatutos". De ahí que toda disposición autonómica sobre la función pública universitaria pase más bien por la coordinación y la base común de determinados aspectos de la prestación del servicio del PAS funcionario de las universidades de su ámbito territorial ${ }^{105}$ y por el régimen de supletoriedad sobre las restantes normas de función pública ${ }^{106}$.

103 Así, por ejemplo, la Resolución Rectoral de 1 de abril de 2014 por la que se aprueba el Reglamento de provisión de puestos de trabajo del personal de Administración y servicios funcionario de la Universidad de Sevilla.

${ }^{104}$ El Cuerpo de Catedráticos de Universidad, de Profesores Titulares de Universidad y de Titulares de Escuela universitaria "a extinguir" son Cuerpos especiales (según la denominación del art. 24 de la LFCE), adscritos al Ministerio de Educación y Ciencia.

${ }^{105}$ Un buen exponente de lo que expresamos, por ejemplo es el "II Acuerdo sobre las condiciones de trabajo del personal de administración y servicios funcionario de las Universidades públicas de Madrid”.

(BOCM 21 de Julio de 2005)

106 Buena prueba de esto es la Resolución administrativa de la Universidad Autónoma de Madrid que ahora transcribimos: "Resolución de 22 de junio de 2015, del Rector, por la que se publica la modificación parcial de puestos de trabajo del personal de administración y servicios funcionario de esta Universidad. Aprobada la modificación parcial de la relación de puestos de trabajo del personal funcionario de administración y servicios de esta Universidad por Acuerdo del Consejo de Gobierno de 19 de junio de 2015, y a efectos de dar cumplimiento a lo previsto en el artículo 15.3 de 
De hecho, algunas leyes de función pública autonómicas -las pocas que en la actualidad se refieren al PAS funcionario de las universidades públicas- matizan su aplicación directa con formulas del siguiente tenor: "el personal funcionario de administración y servicios de las universidades públicas gallegas se rige por la presente ley en todo lo que no esté expresamente regulado por la ley orgánica de universidades y sus disposiciones de desarrollo ${ }^{107}$ "; o con una formula de extraordinaria simpleza: "la presente Ley se aplica también al personal de las universidades, respetando la autonomía universitaria ${ }^{108}$ ". Incluso se llega a distinguir entre el término "regirse", como fórmula de "guía o de gobierno" del sistema de fuentes aplicable al estatuto del PAS funcionario, del término "es aplicable", no sabemos muy bien si con la intención de referirse a un caso particular el general aplicable para el conjunto de funcionarios autonómicos, algo que es absurdo, por cuanto que el sistema de fuentes definido por una ley cabecera, no admite alteraciones por la propia norma sectorial encargada de singularizarlo o bien para precisarlo. Algo tan sencillo como que una cosa no puede ser y ser al mismo tiempo ${ }^{109}$. Más bien entendemos que en este último caso el legislador autonómico podía referirse con la fórmula "es aplicable" a una especie de régimen de supletoriedad de la normativa autonómica de función pública, sobre las disposiciones específicas y particulares aplicables al PAS funcionario. Lo cual viene a reafirmarnos en el carácter supletorio de la legislación de función pública de las CCAA respecto del estatuto del PAS funcionario de las universidades públicas.

la Ley 30/1984, de 2 de agosto, de Medidas para la Reforma de la Función Pública, modificada por la Ley 23/1988, de 28 de julio, y en el artículo 74 de la Ley 7/2007, de 12 de abril, del Estatuto Básico del Empleado Público, así como a lo establecido en los artículos 4.e) y 29.c) de los Estatutos de la Universidad, aprobados por Decreto 214/2003, de 16 de octubre, del Consejo de Gobierno de la Comunidad de Madrid (Boletin Oficial de la Comunidad de Madrid de 29 de octubre), modificados por Decreto 94/2009, de 5 de noviembre, del Consejo de Gobierno de la Comunidad de Madrid (Boletín Oficial de la Comunidad de Madrid de 4 de diciembre), y de conformidad con lo previsto en el artículo 2, párrafo 2.i), de la Ley Orgánica 6/2001, de 21 de diciembre, de Universidades, modificada por la Ley Orgánica 4/2007, de 12 de abril, esta Gerencia, en uso de las atribuciones que en materia de personal tiene delegadas por Resolución Rectoral de 10 de abril de 2015 (Boletín Oficial de la Comunidad de Madrid de 17 de abril de 2015),"

107 Art. 8, de la Ley 2/2015, de 29 de abril, de empleo público de Galicia.

108 Art. 2.2 b) del Decreto Legislativo 1/1997, de 31 de octubre, por el que se aprueba la refundición en un texto único de los preceptos de determinados textos legales vigentes en Cataluña en materia de función pública. Disposición que parece contradecirse con el art. 74.1 de la Ley 1/2003, de 19 de febrero, de universidades de Cataluña, al señalar que "El personal funcionario de administración y servicios de las universidades públicas se rige por la presente Ley, sin perjuicio de las bases estatales establecidas por la Ley orgánica 6/2001, de 21 de diciembre, de universidades, y la Ley 30/1984, de 2 de agosto, de medidas para la reforma de la función pública, por la normativa dictada en su desarrollo y por los estatutos u otra normativa interna de las universidades. El personal laboral de administración y servicios se rige, además, por la legislación laboral y por los convenios colectivos que le sean aplicables". Lo cual nos lleva a pensar en una derogación tácita de aquélla disposición.

${ }^{109} \mathrm{He}$ aquí el fruto de nuestra perplejidad recogido por el apartado $2^{\circ}$ del articulo citado en nues- 


\section{3. “...y por los Estatutos de su Universidad." ¿Podrían constituir éstos formalmente el Estatuto jurídico pecu- liar del PAS funcionario?}

Sobre la naturaleza jurídica de los Estatutos, el Tribunal Supremo siguiendo la doctrina del Tribunal Constitucional, afirma que "aunque tengan su norma habilitante en la Ley de Reforma Universitaria, no son en realidad normas dictadas en su desarrollo, sino reglamentos autónomos en los que se plasma la potestad de autoordenación de la Universidad en los términos que permite la ley, por lo que solamente puede tacharse de ilegal alguno de sus preceptos si contradice frontalmente las normas legales que configuran la autonomía universitaria, siendo válida toda norma estatutaria respecto de la cual quepa alguna interpretación legal ${ }^{10}$ ", de la misma forma que son la primera manifestación de la autonomía universitaria ${ }^{111}$. De ahí que la LOU, en alguno de sus preceptos, remita directamente a los Estatutos universitarios la regulación de determinados aspectos del estatuto del PAS funcionario tales como la provisión de puestos de trabajo de la administración universitaria, la selección de este mismo, la representación y participación del PAS funcionario en los órganos de Gobierno de la Universidad o también aspectos relacionados con su régimen retributivo. Cabe, pues, una acción normativa sustancial por parte de estos dentro de los contornos de la legislación básica de función pública estatal, tal y como hemos adelantado más arriba, bajo el amparo del régimen de autonomía universitaria.

El papel, pues, de los Estatutos universitarios iría más allá del régimen de supletoriedad, teniendo un papel de complementariedad real de la normativa básica estatal tanto sectorial, es decir desde las competencias en materia de universidades, como desde las generales de función pública. Podríamos incluso afirmar que los Estatutos de las universidades podrían ser los elementos configuradores de un "estatuto" jurídico propio para el PAS funcionario de la universidad pública correspondiente,

\footnotetext{
tra nota anterior de la Ley 1/2003, de 19 de febrero, de universidades de Cataluña: "Al personal funcionario de administración y servicios de las universidades públicas de Cataluña le es aplicable la normativa de la función pública de la Administración de la Generalidad, aprobada por el Decreto legislativo 1/1997, de 31 de octubre, y, en especial, los preceptos relativos a la adquisición y la pérdida de la condición de funcionario, las condiciones y los procedimientos de acceso, la provisión y la promoción, las situaciones administrativas, los derechos, los deberes y las responsabilidades y el régimen retributivo, con las adaptaciones necesarias a las peculiaridades de organización y funcionamiento de la universidad".

${ }^{110}$ STS, contencioso sección 7, de 30 de junio de 1998 (ROJ: STS 8666/1998) No de Recurso: 6449/1995 |Ponente: GUSTAVO LESGURE MARTIN. En este mismo sentido la STS, contencioso sección 7, de 3 de julio de 2001 (ROJ: STS 5724/2001) No de Recurso: 6633/1995 |Ponente: JUAN JOSÉ GONZÁLEZ RIVAS.

${ }^{111}$ Art. 2.2 a) de la LOU.
} 
incardinándose directamente en la Ley orgánica de Universidades. Como quiera que la realidad normativa universitaria no ha optado por esta solución, el resultado ha sido más bien un estatuto del PAS funcionario constituido por un grupo normativo, es decir por el conjunto de todas las normas jerárquicamente ordenadas y completas, que contemplan un mismo supuesto de hecho abstracto bajo una misma ratio o finalidad. Ese "espacio normado" está integrado por una serie de disposiciones reglamentarias que van concretando el contenido de la ley formal ${ }^{112}$. De ahí que podemos hablar de un grupo normativo general, en el caso del estatuto del PAS funcionario, constituido, en primer término, por la ley orgánica de universidades, la legislación y normas de desarrollo de ésta, por todo el denominado Estatuto común de los funcionarios públicos y otros subgrupos normativos, intrínsecamente unidos a aquél, constituidos por los diversos Estatutos funcionariales estatales y, en menor medida de entes territoriales. Esta fórmula estatutaria es cualquier cosa menos simple y sencilla, aunque este estatuto tendría como origen una ley especial - la LOU- con la colaboración -en este caso necesaria e imprescindible- de los estatutos universitarios que lo que crean es "un ordenamiento especifico y diferenciado, sin perjuicio de las relaciones de coordinación con otros ordenamientos en los que aquél necesariamente ha(n) de integrarse ${ }^{113}$ ".

De esta manera, los Estatutos universitarios, a pesar del sistema de fuentes establecido en el art. 73.3 de la LOU, son pieza clave dentro del Estatuto de los funcionarios del PAS de las universidades públicas aunque su grupo normativo está directamente vinculado al ámbito legislativo estatal en virtud de la propia ley orgánica.

\section{GONGLUSIONES}

Legislación sectorial sobre universidades, tanto la que se promulgara en 1983 como la LOU de 2001, y su reforma de 2007, no ha realizado un tratamiento suficiente del Estatuto del PAS funcionario de las Universidades públicas, no sabemos si con la intención de tan sólo señalar sus singularidades, por serles de aplicación en su integridad el Estatuto de los funcionarios de la administración territorial correspondiente -la AGE o de las CC.AA-, o bien con la idea de que fueran objeto de regulación específica en desarrollo de la LOU, o también con la idea de que los Estatutos de las universidades fueran su marco regulatorio. Lo que si parece claro es que su no

\footnotetext{
${ }^{112}$ José Luis Villar Palasí y José Luis Villar Ezcurra (1999) 'Principios de Derecho Administrativo I'. Servicio de Publicaciones de la Universidad Complutense de Madrid. 4a edición. Madrid. Pág. 260.

113 STC 55/1989, de 23 de febrero de 1989. Rec. incons. n 1342/1986.
} 
transferencia a las CC.AA hace que estos funcionarios no se integren en las respectivas funciones públicas autonómicas, y que las referencias que la LOU realiza a la acción normativa de éstas respecto del PAS funcionario no pasaría de regular lo estrictamente necesario para posibilitar un régimen retributivo y de condiciones de prestación del servicio lo suficientemente coordinado para que no se produzcan diferencias no razonables, junto al carácter supletorio de sus normas de función pública. Pero sobre el modelo tradicional de función pública territorial ¿qué son los funcionarios del PAS de las universidades públicas: son funcionarios autonómicos, estatales o simplemente funcionarios de las Universidades?

El PAS funcionario carece formalmente de un estatuto jurídico específico de tal manera que, en realidad su normas reguladoras se contienen en un régimen estatutario heterogéneo, en los que los principios de competencia y especialidad son básicos dado que las tres administraciones implicadas -Estado, CCAA y universidadestienen competencia normativa al respecto. Por tanto, competencia y especialidad son los principios que pueden interactuar para poder establecer una solución en el acertijo normativo propio de su Estatuto material ${ }^{114}$. De lo que no cabe duda alguna es que la Ley Orgánica de Universidades es la norma "cabecera" de un subsistema normativo - su estatuto- que puede contener tanto normas de desarrollo estatales de la misma ley orgánica, como normas generales de función pública directamente vinculadas al Estatuto de los funcionarios al servicio del AGE, en la medida que éstas mismas lo prevean, junto a los Estatutos de las Universidades que se añaden a las anteriores en los casos de remisión directa por parte de la LOU. La legislación autonómica sólo sería aplicable, en realidad, en última instancia de las anteriores para la materia que la propia LOU haya previsto - techo máximo de retribuciones y programas de incentivos ligados a méritos individuales vinculados a su contribución en la mejora de la investigación y la transferencia de conocimiento- y sobre aquéllas materias que redunden en la coordinación de las condiciones de la prestación del servicio, junto a un régimen de supletoriedad general. Todo lo cual nos lleva a afirmar que el PAS funcionario de las universidades públicas gozaría de un Estatuto material peculiar, al modo del régimen estatutario de los funcionarios docentes, incardinado en la normativa estatal a través del art. 1.2 de la Ley 30/1984, de 2 de agosto, con

${ }^{114}$ El Tribunal Constitucional se manifestaba de forma muy evidente -y plástica diríamos- respecto del Estatuto de otro grupo de funcionarios - la policías locales- con una situación jurídica análoga a la ahora tratada: "en el conjunto a veces muy complejo de remisiones en cadena y hasta de reenvíos mutuos, a su vez con salvedades o excepciones de excepciones que enturbian en alguna ocasión el entendimiento de la voluntas legis". STC, constitucional pleno, de 21 de enero de 1993 (STC 25/1993). Recurso de inconstitucionalidad 1.753/1988 |Ponente: RAFAEL DE MENDIZÁBAL ALLENDE. 
las peculiaridades establecidas por el Título X de la Ley Orgánica de Universidades, y que les caracteriza por ser funcionarios estatales.

\section{BIBLIOGRAFÍA}

CASTILLO BLANCO, Federico (2009)“El Estatuto Básico del Empelado Público y el régimen del personal al servicio de las Universidades públicas", en la obra "Comentario a la Ley Orgánica de Universidades”. Coord. por Julio V. González García. Ed. Civitas - Thomson Reuters. Madrid

GIL FRANCO, Agustín J. (2014) "Elementos necesarios o estructurales de las relaciones de puestos de trabajo del personal funcionario en el Estado y los municipios desde las normas y la jurisprudencia" Revista Vasca de Administración Pública. Rev. No 99/100

GIL FRANCO, Agustín J. (2015) "Régimen jurídico básico de las relaciones de puestos de trabajo y estatuto de los funcionarios locales" Revista de Estudios de Administración Local y Autonómica. INAP, no 3. Enero-junio 2015

GÓMARA HERNÁNDEZ, José Luis (2009) "El personal de administración y servicios de las Universidades públicas" en la obra Comentario a la Ley Orgánica de Universidades”. Coord. por Julio V. González García. Ed. Civitas - Thomson Reuters. Madrid.

GÓMEZ-PANTOJA GUMPLIDO, Joaquín (1999) "El régimen de la función pública aplicable al personal de administración y servicios de las Universidades: conciliación y aplicabilidad de las disposiciones estatales, Ley de Reforma Universitaria y Estatutos universitarios" en la obra "Las Universidades públicas y su régimen jurídico". Ed. Lex nova. Valladolid

TARDIO PATO, J. A. "El derecho de las universidades públicas españolas". Vol. II Ed. PPU. Barcelona. 